\title{
A Typology of Consonant Agreement as Correspondence*
}

\author{
Sharon Rose and Rachel Walker \\ University of California, San Diego and University of Southern California
}

1. INTRODUCTION. The action at a distance that is characteristic of consonant harmonies stands as a pivotal problem to be addressed by phonological theory. Consider a familiar example from Chumash. The character of coronal fricatives and affricates in Chumash is determined by the rightmost coronal sibilant (1a). This agreement alters /s/ to [S] when preceding a root or suffix palatoalveolar (1b), and conversely / $/ /$ is realized as [s] when preceding [s] (1c). The rightmost sibilant can occur at any distance from the affected fricatives/affricates, and the altered consonants may occur in a root or affix. Data are drawn from Poser (1982) and Shaw (1991).
a. S-api-t 0 o-it
'I have good luck'
s-api-tso-us
b. s-ixut
'it burns'
c. ufla
'with the hand'
S-ilaks
'he has good luck'
'it is soft'
usla-siq
'to press firmly by hand'

Another representative case is seen in the nasal agreement of Kikongo. In this language, the voiced stop in the suffix -idi in (2a) is realized as [ini] in (2b) when preceded by a nasal consonant at any distance in the stem, consisting of root and suffixes (prefix nasals are excluded). The examples are from Piggott (1996).
a. m-bud-idi
'I hit'
n-suk-idi
'I washed'
b. tu-kin-ini
tu-nik-ini
'we planted'
'we ground'

Data such as these are central in the debate on mechanisms of feature agreement and their locality, because they display agreement across strings of apparently unaffected neutral material. Such phenomena raise two fundamental questions: (i) what determines the participating segments in long-distance agreement for a given feature? and (ii) how is the neutrality of intervening segments to be obtained? These issues have stimulated various proposals in the literature on nonlinear phonology that involve linking the agreeing feature between participating consonants; however, we will argue that these accounts are unsatisfactory on the basis of explanatory and theoretical considerations. The aim of this paper is to develop an alternative proposal whereby long-distance agreement is brokered via a correspondence-theoretic relation established between the participant segments. We term this approach Long-Distance Agreement through Correspondence or LDAC. A chief assertion of the LDAC proposal is that agreement is determined by Identity constraints which check feature matching in corresponding consonants, thereby obviating representations in which feature linkage skips over spans of neutral segments. Another key claim is that similarity plays a decisive role in identifying which segments stand in correspondence.

This paper is organized as follows. Section 2 provides a brief background on work that posits featural agreement as the outcome of linkage or spreading and previews the motivation for the

\footnotetext{
* We would like to thank Eric Baković and Kie Zuraw for detailed comments on this paper. For suggestions and comments on this or related work we are also grateful to Laura Benua, Dani Byrd, Bruce Hayes, Larry Hyman, Junko Itô, Linda Lombardi, Maryellen MacDonald, Peggy MacEachern, John McCarthy, Frida Morelli, John Ohala, Jaye Padgett, Alan Prince, Jennifer Smith, Adam Ussishkin, Colin Wilson, Moira Yip, Lisa Zsiga, USC Phon Lunch participants, and NELS 31 audience members.

The author's names are arranged in alphabetical order. We welcome correspondence on matters relating to this work, which we request be addressed to both authors.
} 
correspondence approach in cases of long-distance agreement. In $\$ 3$ we present a cross-linguistic typology of consonant agreement at a distance and discuss our finding that participant consonants typically share a considerable degree of similarity to each other. We proceed to establish the principles of the LDAC approach in connection with the descriptive generalizations that our typology determines. Sections 4 and 5 together demonstrate aspects of the depth and breadth of this model's application through case-studies in long-distance nasal agreement and laryngeal agreement. In $\S 6$ we turn to diagnostics for identifying LDAC agreement versus feature linkage phenomena, and we consider where coronal harmony systems stand in this regard. Finally, in $\$ 7$ we discuss some issues for further study and present the conclusion.

\section{BACKGROUND}

2.1 SPREADING-BASED APPROACHES. In nonlinear phonology, featural agreement phenomena have been analyzed as the product of spreading, that is, through cross-segmental linkage of the agreeing feature. This approach has customarily been adopted both for assimilations that produce agreement between root-adjacent segments and for agreement between segments at a distance. The latter cases depend on the assumption of tier-based locality, which formed the basis for a major body of work focused on representationally-driven explanation. Research in this direction obtains different distances of interactions through geometric organization of feature classes and underspecification of structure (for overviews see Clements \& Hume 1995, Steriade 1995).

One widespread version of tier-based locality determines adjacency at the mother-node for the linking feature. Let us consider again Chumash coronal harmony. Shaw (1991) analyzes agreement for coronal subsidiary features among sibilants in Chumash as the product of spreading the feature [anterior], a daughter of the Coronal node. According to mother-node locality, segments specified with a coronal node are adjacent at the Coronal tier. The neutrality of non-coronal segments is accordingly straightforward, as shown in (3) (see Archangeli \& Pulleyblank 1987, Shaw 1991, Odden 1994 for extensions whereby locality for targets is reckoned at some other tier).

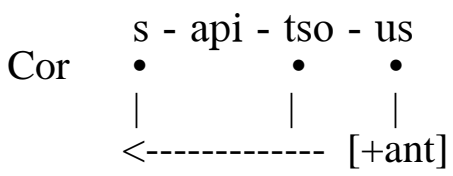

The representation in (3) contains what is called a gapped configuration. We follow Ní Chiosáin \& Padgett (to appear) in taking this to refer specifically to structures where feature linkage gaps across an intervening segment of which it is not an associated property. In work assuming tier-based locality, gapped configurations are admitted provided that association lines do not cross (Goldsmith 1976) and locality at the relevant tier is respected. Such structures have not been limited to harmonies that produce alternations. Morpheme structure constraints (MSCs) have also been analyzed with tier-based linkage of features (Mester 1986, Yip 1989), and have given rise to gapped configurations.

Although the tier-based view of locality represents a significant stage in the theory of phonological locality, subsequent advances in work on long-distance interactions have since called this approach into question. A group of recent studies reveals that many cases of featural agreement that were formerly believed to involve action at a distance in fact represent interactions that do not overlook intervening segments. Ní Chiosáin \& Padgett (to appear) make this claim for transparent consonants in vowel harmony. They argue that the spreading vocalic feature carries through intervening consonants, but they are perceived as transparent, because the spreading vocalic gesture does not have a significant contrast potential in these segments. Other work that argues for this kind of perceptual transparency includes Walker \& Pullum (1999) on transparent glottal stops 
in nasal harmony, and Flemming (1995b), Gafos (1996[1999]) and Ní Chiosáin \& Padgett (1997) on certain coronal harmonies (cf. our discussion of some other cases of coronal agreement in $\S 3.1$ and $\$ 6$ below). Further support for the treatment of 'transparent' segments as participants in spreading comes from studies by McCarthy (1994), Padgett (1995a), Walker (1998[2000]), and Gafos \& Lombardi (1999). Together this research makes a strong case for eliminating the notion of gapping in feature spreading in favor of strict segmental locality, where feature linkage must obey adjacency at the level of the root node (Ní Chiosáin \& Padgett to appear).

A further consideration is that the pursuit of transparency via gapping has in some instances necessitated ad hoc structures. For example, Mester (1986) proposes a tier ordering for voice agreement between homorganic consonants in Ngbaka, wherein [voice] is dependent on C-place, as shown in (4) (adapted from Mester):
a. $\mathrm{t} \mathrm{V} \mathrm{t}$
I 1
b. $\mathrm{d} V \mathrm{~d}$
[Coronal]
[-voice]

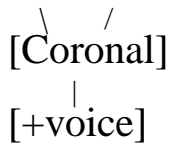

In addition to the doubtful status of the gapped association of a C-place feature across a vowel, the feature organization in these representations is questionable. The dependency of [voice] on C-place is not cross-linguistically motivated-[voice] is generally agreed to belong to a Laryngeal node which stands as a sister to C-place. The language-specific tier ordering in Ngbaka is needed under an approach that assumes the voicing agreement and its homorganicity condition stems from feature linking across segments.

On the other hand, certain types of feature agreement remain problematic for the strict segmental locality approach. Long-distance nasal harmony like that shown in (2) resists a perceptual transparency explanation. If the feature [nasal] were associated to the entire string of segments intervening between the nasal stop and the alternating suffix consonant, all vowels and consonants would be expected to be nasalized. But they are not. Unlike the examples of perceptual transparency noted above, the spreading feature in this instance is expected to be perceptible on the transparent segment. Laryngeal agreement between consonants across vowels is another case in point. If [-voice] were simultaneously associated to two consonants, it should follow that the intervening vowel is also [-voice]. This is not, however, reported in the description of Ngbaka (Thomas 1963). Although [-voice] could conceivably be rendered absent in representations via a monovalent view of features, the problem persists in agreement for [constricted glottis] and [spread glottis] across unaffected vowels, as discussed in $\$ 5$.

To summarize, the treatment of certain kinds of long-distance agreement between consonants is problematic under spreading-based approaches. It entails the assumption of representations that there is reason to reject in the theory. If a more constrained view of representations is adopted, the theory does not predict the possibility of long-distance consonantal agreement for features like [voice] and [nasal] via feature spreading. We take this position as our point of departure.

2.2 PREVIEW OF CORRESPONDENCE-BASED PROPOSAL. We propose that the mechanism that underlies non-local agreement between consonants is not spreading but rather an identity effect that arises between segments that are recognized as similar. We suggest that consonants showing agreement at a distance stand in a relation through which the featural identity of the consonants is mediated (extending ideas discussed in Walker 1999, 2000a,b). The type of configuration with which we will be concerned is represented in (5). 
In this structure a relation has been established between two consonants, as indicated by coindexing. In $\$ 3.3$, we propose to formalize this relation in terms of Correspondence (McCarthy $\&$ Prince 1995, 1999). The featural agreement comes about through the activity of constraints that enforce identity between corresponding segments. Observe that in contrast to spreading-based accounts that admit gapping, the LDAC approach that we advocate here maintains the assumption of strict segmental locality. No feature links that gap across intervening segments are posited in (5).

Before developing the analysis, we present a typology of long-distance consonant agreement and demonstrate the importance of similarity between the interacting segments.

\section{A TYPOLOGY OF LONG-DISTANCE CONSONANT AGREEMENT}

3.1 CROSS-LINGUISTIC OVERVIEW. LDAC encompasses both MSCs and alternations. Every language we have examined that has long-distance alternations also has root structure constraints for the same features. Many cases of long-distance agreement have been labeled 'consonant harmony' in the literature. Yet, this term has also been used to refer to phenomena that do not involve agreement. For example, Shaw (1991) uses the term 'consonant harmony' to refer to processes that entail 'action at a distance', including both assimilatory and dissimilatory processes. Many of the cases cited in her typological list of consonant harmony (Shaw 1991:128-9) are dissimilations; only the coronal harmonies that she lists are true agreement phenomena. We exclude dissimilation from our survey, although we note that there are certain similarities between it and agreement. For a recent overview of dissimilation, see Suzuki (1998). Other uses of the term 'consonant harmony' have included sound symbolism and morphological harmonies such as Salish glottalization or Chaha labialization, ${ }^{1}$ which we also do not address in this paper, as they are generally analyzed as involving floating features or morphological rewrite rules.

3.1.1 AGREEMENT TYPES. The typology of LDAC includes nasal agreement, liquid agreement, laryngeal agreement and coronal agreement. We present each case in turn and point out the similarity of the interacting consonants.

3.1.1.1 NASAL. Nasal agreement over intervening vowels and consonants is found in Kikongo (Ao 1991, Odden 1994, Piggott 1996) and Yaka (Hyman 1995, Walker 2000b). Other Bantu languages such as Bemba (Hyman 1995), Lamba (Doke 1938, Odden 1994, Piggott 1996), and Ndonga (Viljoen 1973) show agreement only over an intervening vowel. Both types are considered long-distance; the latter operates over a shorter distance due to an independent proximity restriction (see Odden 1994, Suzuki 1998 on proximity). Nasal agreement in Ngbaka presents a case outside of Bantu. The key property of nasal agreement that distinguishes it from nasal harmony is that intervening vowels (and other consonants) are not nasalized. Examples of nasal agreement in the Kikongo perfective active suffix following a nasal consonant in the stem domain (root and suffixes) are repeated in (6) from (2). The suffix consonant phoneme is variably

1 Chaha labialization (Leslau 1967) is not actually harmony, but involves the morphological feature of labialization appearing on reduplicated consonants. In Inor (Prunet 1991), a related dialect, the labialization can extend to other velars and labials in the stem. 
realized as [d] or [1] when oral, as we elaborate in $\S 4$.

$$
\begin{array}{llll}
\text { a. } \begin{array}{l}
\text { m-bud-idi } \\
\text { n-suk-idi }
\end{array} & \text { 'I hit' } & \text { b. tu-kin-ini } & \text { 'we planted' } \\
\text { tu-nik-ini } & \text { 'we ground' }
\end{array}
$$

The segments that interact with a nasal in the suffix alternation are voiced stops and oral sonorant consonants. In addition, Kikongo has an MSC wherein these consonants do not appear after a nasal. In the case of Ngbaka, nasals do not cooccur with voiced stops of the same place of articulation.

Among the consonants that participate in nasal agreement, approximant consonants and nasals share the property of being sonorants, and voiced stops and nasals share the property of being voiced non-continuants. This is represented in the following chart. The dissimilarity between nasals and the consonants that do not display nasal agreement is highlighted in the shaded boxes. This is for illustrative purposes only; we contend that mere counting of features is not a sufficient mechanism for calculating similarity. Note that participating consonants share either [son] or [cont] as well as [voice].

\begin{tabular}{|l|l|l|l|l|}
\hline TARGET & TRIGGER & $\begin{array}{l}\text { SHARED } \\
\text { FEATURES }\end{array}$ & $\begin{array}{l}\text { DIFFERENT } \\
\text { FEATURES }\end{array}$ & $\begin{array}{l}\text { AGREEING } \\
\text { FEATURE }\end{array}$ \\
\hline \hline Approximant consonants & Nasal & {$[$ son] $([$ voice $])$} & {$\left[\right.$ cont ${ }^{2}$} & {$[$ nasal $]$} \\
\hline Voiced stops & Nasal & $[$ cont $]$ [voice $]$ & {$[$ son $]$} & {$[$ nasal $]$} \\
\hline Voiceless stops & Nasal & {$[$ cont $]$} & {$[$ son] $[$ [voice $])$} & - \\
\hline Voiced fricatives & Nasal & {$[$ voice $]$} & {$[$ son] $[$ cont $]$} & - \\
\hline
\end{tabular}

3.1.1.2 LIQUID. LDAC also affects liquids, although interaction among liquids is more commonly dissimilatory in nature. In Bukusu, /l/ in the benefactive suffix /-ila/ shown in (8a) becomes [r] after a stem containing [r] in (8b) (Odden 1994). The quality of the suffix front vowel is regulated by height harmony.
a. teex-ela 'cook for' lim-ila 'cultivate for' iil-ila 'send thing'
b. kar-ira 'twist' reeb-era 'ask for' resj-era 'retrieve for'

Liquid agreement operates over intervening vowels and other non-liquid consonants. The segments are highly similar, differing only for the alternating feature, which we assume to be [rhotic] (Walsh-Dickey 1997). In Kipare (Odden 1994), the glide /j/ of the perfective suffix /-ije/ and applied suffix /-ija/ is realized as [r] following [r] and as [1] following [1] ([lateral] agreement) in the immediately preceding syllable. Again, the segments interacting are all sonorous approximants. ${ }^{3}$

2 It is possible that the [1] of Kikongo is [-cont], in which case this particular segment would agree with nasals in this property as well.

A separate optional phenomenon changes the glide $/ \mathrm{j} /$ to a palatal stop $[\mathrm{f}]$ when a palatal consonant $\left[\int \mathrm{f} \mathrm{j}\right.$ ] occurs in the preceding syllable, e.g. /ku-min-ij/ --> [kuminija] 'to press for'. On the surface, this appears to be an agreement for [consonantal] between palatal segments, as this is the only feature shared by the three palatal consonants. Yet, Hume \& Odden (1996) have argued against the feature [cons]. Instead, we suggest that the fortition effect is conditioned by the intervening high vocoid. An [i.j] sequence of two high front vocoids is dispreferred, an OCP effect (Rosenthall 1994[1997]). Although generally tolerated in the language, this sequence is worsened by the presence of a preceding palatal consonant which shares place of articulation with the glide. The two compounding 
3.1.1.3 LARYNGEAL. The laryngeal features are [voice], [spread glottis] ([sg]) and [constricted glottis] ([cg]) (Lombardi 1991). The feature [sg] characterizes aspirated segments and [cg] marks ejectives, implosives and other glottalized segments. All these features show LDAC effects among oral stops. In addition, a homorganicity restriction may be imposed on the agreement.

VOICE. In Kera, voiceless velar stops in prefixes and suffixes are voiced if the stem contains voiced oral stops and affricates; other voiced segments do not trigger the voicing agreement (Ebert 1979, Odden 1994, Walker 2000a).
a. $\quad / \mathrm{kV}$-gə̀r/ $\rightarrow \quad$ [gə̀gə̀r]

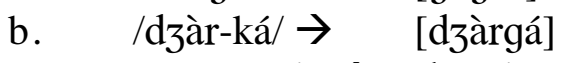
c. $\quad / \mathrm{kV}$-màanว̀/ $\rightarrow$ [kəmàanò] *[gəmàanò]
'knee'
d. /kV-sár-káy/ $\rightarrow$ [kəsárkáy] *[gəsárgáy]
'colorful' (fem.)
'woman'
'black' (coll.)

In Chaha, a Semitic language, stops in a root must agree for voicing (Banksira 2000). Hence, roots with *kd or *gt are disallowed; fricatives do not participate in the restriction, so we find roots such as /kz $\beta /$ 'become inferior' or $/ \mathrm{sd} \beta /$ 'curse'. ${ }^{4}$ Voicing restrictions on stops also hold in stems in Ngbaka (Thomas 1963, 1970, Mester 1986, Walker 2000a), with an additional caveat that the stops must be homorganic. In summary, voicing agreement holds between oral stops. We have found no cases where it operates between both fricatives and stops.

SPREAD GLOTTIS AND CONSTRICTED GLOTTIS. The other laryngeal features, [sg] and [cg] exhibit fewer active alternations in affixes, but do demonstrate MSCs. These constraints, which require that oral stops match for [cg] or [sg], may hold over homorganic stops or stops in general. In Yucatec Mayan (Straight 1976, Yip 1989) homorganic stops and affricates must match for [cg] to cooccur in a root. Roots such as *k'Vk are ruled out. If both consonants are [cg], they must be identical, so *t'Vk' is impossible. MacEachern (1997[1999]) documents several cases of laryngeal constraints requiring agreement among homorganic stops in roots. For example, in Bolivian Aymara, Hausa and Tzujutil, stops are not required to agree for place, but if they do, then they must match for [sg] or [cg] specifications. This restriction holds over stops separated by both vowels and consonants. Other languages have no restrictions on the homorganic nature of stops. In Chaha (Banksira 2000), stops in a root may not differ in laryngeal specification, being either ejectives or voiced, as we saw above. The Bolivian Aymara and Chaha cases are analyzed in $\S 5$.

In all of these languages, [sg] and [cg] are characteristic of stops/affricates only. While glottalized fricatives are possible, they are rare and are often realized phonetically as affricates. Fricatives are not aspirated, although Vaux (1998) has argued that [sg] can characterize plain voiceless fricatives. The inventories of some languages contain glottalized sonorants, and these often behave differently from other glottalized segments. For example, in Coeur d'Alene, a morphological floating [cg] feature is realized only on sonorants, even though ejectives exist in the language (Reichard 1938, Cole 1987). Although this has been analyzed as a type of harmony phenomenon, since it is a morphological feature, we do not address it here. Archangeli \& Pulleyblank (1994) document a similar separation of sonorants and obstruents as targets for docking of a floating [cg] feature in Yawelmani.

We hypothesize that the scarcity of [sg] and [cg] alternations in affixes is due to the propensity of glottalized and aspirated segments to occur primarily in roots and not affixes. Languages of this type include Cuzco Quechua (Parker \& Weber 1996) and Chaha (Banksira 2000). McCarthy \&

OCP effects (which could be modeled using local conjunction) are alleviated by adjusting the vocoid status of the [j] to [f], which preserves place and voice features and also creates a more respectable sonority contour.

4 There is only one voiced fricative [z] in Chaha, and forms like the verb [wizf] 'procrastinate' and noun [zəfər] 'track, trace' suggest that fricatives do not agree for [voice]. 
Prince $(1995,1999)$ observe that marked segments such as pharyngeals tend not to occur in affixes. They attribute this to a meta-constraint ranking Root-Faith > Affix-Faith. Roots are subject to special positional faithfulness constraints in comparison to affixes (Beckman 1998, Pater 1999). We make the uncontroversial assumption that glottalized and aspirated stops are marked in relation to their plain counterparts.

3.1.1.4 CORONAL. There are three types of coronal LDAC: 'sibilant' agreement, dental agreement and retroflex agreement. All involve features that refer to the tongue blade/tip (Gafos 1996[1999]) and are therefore only relevant or subsidiary to coronals.

SIBILANT. The most common type operates among sibilant fricatives and affricates, producing alternations such as $[\mathrm{s}] /\left[\int\right]$. This is often termed sibilant harmony ${ }^{5}$ and is documented in many Native American languages, including Chumash, Navaho, Tahltan, Chilcotin, Chiricahua Apache, Kiowa Apache, Tzutujil, Southern Paiute and Tzeltal. It is also found in Imdlawn Tashlhiyt Berber, Moroccan Arabic, Bantu languages such as Kinyarwanda and Kirundi, and Omotic languages such as Zayse and Aari. The key characteristic of sibilant harmony is that it applies between fricatives and affricates, but oral stops and all other consonants and vowels are transparent. An example from Aari (Hayward 1990) is given below with the causative suffix /-sis/, which is realized as [Si $\left.\int\right]$ following palatoalveolar affricates or fricatives anywhere in the preceding stem (10b). Note that the initial suffix consonant is voiced adjacent to a voiced obstruent.
a. gi?- 'hit'
duuk- 'bury'
sug- 'push'
Pits- 'eat'
gi?-sis- 'cause to hit'
duuk-sis- 'cause to bury'
b. nạf- 'like, love'
sug-zis- 'cause to push'
3ạ- 'throw'
Pittsis- 'cause to eat'
t 'ạạq- 'curse, swear an oath'
nạf-Sif- 'cause to like'
3ạ- $\int \mathrm{i} \int$ 'cause to throw'
Saan- 'urinate'

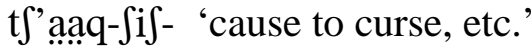
3ạag- 'sew'

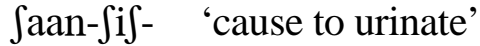
3ạg-3if- 'cause to sew'

In Kinyarwanda (Kimenyi 1979:43) sibilant agreement operates in the opposite direction: alveolar fricatives in the root become palatoalveolar when preceding a palatoalveolar fricative in a suffix:
a. /ku-sas-a/
[gusasa]
'to make bed'
/ku-sas-iif-a/ [gufajiifa]
b. /ku-soonz-a/
[gusoonza]
'to cause to make the bed'
/ku-soonz-iif-a/
[gufoonzee $\left.\int \mathrm{a}\right]$
'to get hungry'
'to cause to make get hungry'

In many languages, directional sibilant harmony occurs irrespective of affix/root affiliation of the sounds and may produce an assimilation pattern that converts, for example, /s/ to $\left[\int\right]$ and $/ S /$ to $[\mathrm{s}]$. Although sibilant harmony is most commonly regressive, the Aari case shows that regressive directionality is not a general property of sibilant agreement.

DENTAL. The second type of coronal LDAC operates among stops and is found in languages with alveolar-dental contrasts. It is particularly prevalent in Nilotic languages, such as Mayak (Andersen 1999), Shilluk (Gilley 1992), Anywa (Reh 1996), Paeri (Andersen 1988) and Luo

\footnotetext{
5 The term 'sibilant' is strictly inaccurate, since at least in Tahltan, harmony involves interdental non-sibilant fricatives.
} 
(Stafford 1967, Yip 1989, Tucker 1994). In most of these languages, agreement is only found as an MSC holding over the cooccurrence of alveolar and dental stops. In those languages that allow dental nasals, the constraints also hold of nasal stops. In Anywa (Reh 1996), there is no cooccurrence of dental and alveolar stops in a root. In addition, a root final [1] or [r] is realized as a voiced alveolar stop with the patient-deleting suffix /-o/, as in (12a). If following a root initial dental stop, however, it must be dental as in (12b). A similar process is found in Paeri (Andersen 1988). ${ }^{6}$
a. d̄̄l dùdò 'to fold something'
nūur núudó 'to press something down'
lier líedó 'to hang'
b. dīir dìdò 'to jostle'
tōōr tòodò 'to finish'

Since roots are of the shape $\mathrm{CV}(\mathrm{V}) \mathrm{C}$, there are no intervening consonants that can be examined for transparency or opacity to the agreement.

In Mayak, alternations are found in the affixes themselves, and unlike Anywa, agreement converts a dental stop to alveolar rather than alveolar to dental. The singulative suffixes /-عt/ and $/-\Lambda \mathrm{t} /$ and the suffix /-it/ may optionally be realized with an alveolar [t] when the root contains an alveolar stop, including the implosive stop [d] (13b). Coronal sonorants neither trigger nor block agreement. The alveolars $/ / /$ and $/ \mathrm{n} /$ fail to cause harmony as shown in (13a). They also do not block agreement, as seen in (13b). Only oral stops show the dental/alveolar contrast and it is only among these forms that agreement operates.

$$
\begin{array}{ll}
\text { a. becl-et } & \text { 'cane' } \\
\text { yaj-it } & \text { 'snail' } \\
\text { ?'in- } \Lambda_{n} & \text { 'intestine' }
\end{array}
$$

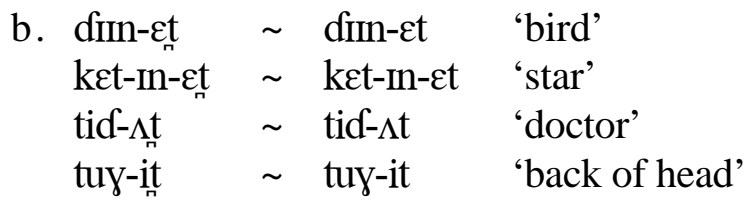

We will revisit the dental/alveolar agreement patterns in $\$ 6$.

RETROFLEX. The third type of coronal agreement involves retroflexion. Breeze (1990:10) reports that in Gimira (Benchnon), an Omotic language of Ethiopia, 'no two palatoalveolar fricatives or affricates within a root morpheme can differ in the feature of retroflexion' ${ }^{7}$ Gimira has a series of plain coronal obstruents [ $\left.t \mathrm{ts} t \int \mathrm{t} \int^{\prime} \mathrm{s}, \mathrm{z}, \int, 3\right]$ and retroflex [ts ts' $\mathrm{s}$ z] such that palatoalveolar fricatives and affricates contrast for retroflexion. Roots such as the following are attested. The numbers indicate tone levels.

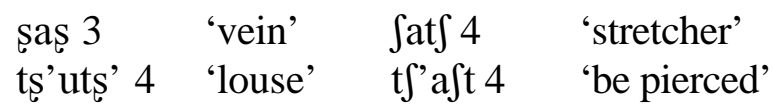

The causative affix /-s/ shown in (15a) undergoes retroflex and palatoalveolar agreement with preceding root segments, as in (15b). A final root segment is often dropped; single final alveolar stops fuse with the suffix to form an affricate:

$$
\begin{aligned}
& \text { Stem Causative }
\end{aligned}
$$

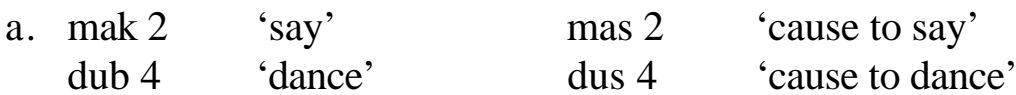

\footnotetext{
$6 \quad$ Note that dental stops in these languages may be pronounced phonetically with affrication.

7 Breeze does not mention root cooccurrence restrictions on alveolars and palatoalveolars, as found in other Omotic languages. However, we could find no examples of this cooccurrence in the data provided in her article.
} 


$\begin{array}{llll}\text { kit } 1 & \text { 'draw water' } & \text { kits 1 } & \text { 'cause to draw water' } \\ \text { b. zert 1 } & \text { 'be red' } & \text { zers 1 } & \text { 'make red' } \\ \text { sup 3 } & \text { 'slaughter' } & \text { sus 3 } & \text { 'cause to slaughter' } \\ \text { ts'ud' } & \text { 'spit' } & \text { ts'uts' } & \text { 'cause to spit' } \\ \text { Jid 3 } & \text { 'remain' } & \text { Sits 3 } & \text { 'cause to leave' }\end{array}$

Some Australian languages also contrast stops at different places of articulation or tongue tip orientation, but few effects of consonant harmony are attested. There are retroflexion alternations discussed in McGregor (1990) and Hamilton (1993) involving apical consonants. In Gaagudju, a word-initial apical alveolar stop is realized as retroflex if the following consonant is retroflex across an intervening vowel. Evans (1995) states that in Mayali, apical stops and nasals (but not retroflex /. $\mathrm{x} /$ ) separated by only a vowel agree in retroflexion. Sanskrit retroflex agreement is another oftcited case of retroflex harmony. We will return to it in $\S 6$.

All three coronal agreement cases show alternation for features that refer to the tongue tip or tongue blade; Gafos (1996[1999]) argues that coronal harmonies involve either the feature [tongue tip constriction area] ([TTCA]) or the feature [tongue tip constriction orientation] ([TTCO]). ${ }^{8}$ Segments are highly similar in sibilant harmony in that only fricatives and affricates participate to the exclusion of stops. The dental/alveolar alternation involves only stops, either oral or nasal. Finally, retroflexion involves either stops or fricatives/affricates. It may also include nasals and rhotics if the language contrasts alveolar and retroflex sonorants.

3.1.2 SIMILARITY AND FEATURES. LDAC phenomena share the general property that the interacting segments bear a high level of 'similarity'. The notion of 'similarity' in MSCs has previously been noted by Pierrehumbert (1993), Frisch (1996), Frisch et al. (1997), and MacEachern (1997 [1999]), although these works deal with dissimilatory constraints. Pierrehumbert (1993) computes similarity by counting the number of features that segments have in common under a contrastive underspecification model of feature specification. In this account, major place features and sonority are assigned first, implicitly attributing more importance to these features in computing similarity than minor features such as [voice] or [anterior]. Frisch (1996) and Frisch et al. (1997) adopt instead a model of 'structured' specification referring to a hierarchy of natural classes of features under the theory developed in Broe (1993). Similarity is computed by dividing the shared natural classes of two segments by the addition of the shared natural classes and non-shared natural classes of the two segments. While such an approach incorporates redundant features into the computation, it does not address the inherent difference between features in both their descriptive and functional properties. We show that [sonorant], [continuant] and place features are the most important in computing similarity; conversely, these features are not those required to agree in distance agreement.

The following table summarizes our findings with respect to LDAC:

8 In Gafos (1996), [TTCA] was referred to as [cross-sectional channel] or [CSC]. [TTCO] was [tongue tip orientation] or [TTR]. Gafos also allows the possibility that Chumash coronal harmony (s/S alternation) involves the feature tongue tip orientation [TTR] rather than [CSC]. These features might raise a problem for a language such as Gimiron which has both retroflex and anteriority harmony among fricatives, unless the two features may cooccur on a single segment. 


\begin{tabular}{|c|c|c|c|c|}
\hline TYPE & SUB-TYPE & $\begin{array}{l}\text { EXAMPLE } \\
\text { LANGUAGE }\end{array}$ & $\begin{array}{l}\text { INTERACTING } \\
\text { SEGMENTS }\end{array}$ & SHARED FEATURES \\
\hline \multirow[t]{3}{*}{ Laryngeal } & voice & $\begin{array}{l}\text { Kera } \\
\text { (Ebert 1979) }\end{array}$ & Oral stops & [-cont, -son] \\
\hline & $\begin{array}{l}\text { constricted } \\
\text { glottis }\end{array}$ & $\begin{array}{l}\text { Chaha } \\
\text { (Leslau 1979) }\end{array}$ & Oral stops & [-cont, -son] \\
\hline & $\begin{array}{l}\text { spread } \\
\text { glottis }\end{array}$ & $\begin{array}{l}\text { Aymara } \\
\text { (MacEachern } \\
\text { 1997[1999]) }\end{array}$ & Oral stops & [-cont, -son] \\
\hline Nasal & & $\begin{array}{l}\text { Kikongo } \\
\text { (Meinhof 1932, } \\
\text { Ao 1991, etc.) }\end{array}$ & $\begin{array}{l}\text { Voiced stops or } \\
\text { consonantal } \\
\text { approximants }\end{array}$ & $\begin{array}{l}{[\text {-cont, +voice }] \text { or }} \\
{[+ \text { son }]}\end{array}$ \\
\hline \multirow[t]{2}{*}{ Liquid } & rhotic & $\begin{array}{l}\text { Bukusu } \\
\text { (Odden 1994) }\end{array}$ & Liquids & $\begin{array}{l}\text { [+cont, +son, Cor, } \\
\text { +cons }]\end{array}$ \\
\hline & lateral & $\begin{array}{l}\text { Kipare } \\
\text { (Odden 1994) }\end{array}$ & Approximants & [+cont, +son, Cor $]$ \\
\hline \multirow[t]{3}{*}{ Coronal } & sibilant & $\begin{array}{l}\text { Aari } \\
\text { (Hayward 1990) }\end{array}$ & $\begin{array}{l}\text { Fricatives \& } \\
\text { affricates }\end{array}$ & [+cont, -son, Cor] \\
\hline & retroflex & $\begin{array}{l}\text { Gimira } \\
\text { (Breeze 1990) } \\
\text { Mayali } \\
\text { (Evans 1995) }\end{array}$ & $\begin{array}{l}\text { Fricatives \& } \\
\text { affricates or } \\
\text { Stops \& affricates }\end{array}$ & $\begin{array}{l}\text { [+cont, -son, Cor }] \\
\text { [-cont, Cor }]\end{array}$ \\
\hline & dental & $\begin{array}{l}\text { Mayak } \\
\text { (Andersen 1999) }\end{array}$ & Stops (affricates) & [-cont, Cor] \\
\hline
\end{tabular}

A number of observations are in order. First, the features that all consonants participating in a given agreement share are [son] or [cont] or both. These are the key features that establish the degree of similarity of interacting segments. Second, laryngeal and nasal agreement are not restricted to operate between coronal segments only. Accordingly, homorganicity is an independent requirement that may be imposed on these agreement patterns. We also find similarity for [voice] imposed on nasal agreement. Third, laryngeal specifications do not impact Coronal agreement. For example, sibilant agreement may obtain regardless of the $[\mathrm{cg}]$ or [voice] features of the interacting consonants, as seen with the Aari example in (10). Similarly, dental and retroflex agreement operates between stops regardless of voicing. Nasal stops may or may not interact in these types of coronal agreements, depending partly on the nasal stop contrasts available in the language. See $\S 6$ for more details.

The features [cont] and [son] define the stricture properties of consonants. The feature [cont] sets apart stops from other sounds, and long-distance agreement can operate between all stops, both nasal and oral, to the exclusion of other sounds. The feature [son] separates sounds with some obstruction in the vocal tract from those that have a relatively open channel. We find longdistance agreement between glides and liquids, and between approximants and nasals. Interestingly, we have not observed agreement between all [+cont] sounds (sonorant continuants and oral fricatives) or all [-son] sounds (all obstruents). Sibilant harmony occurs between Coronal [+cont] sounds, but if Gafos (1996[1999]) is correct, this is due to the nature of the agreeing tongue tip constriction feature rather than constriction in general. The restriction to [-cont] and [+son] appears to suggest that we are dealing with monovalent features [stop] and [sonorant]. Nevertheless, some processes such as local voicing assimilation apply only among obstruents, and 
it would appear that [-son] is still a useful classification outside of long-distance agreement. Finally, the place of articulation of agreeing sounds is important. The Coronal region subsumes a much larger class of consonants than other places of articulation. Agreement may operate within the Coronal class for features such as tongue tip/blade orientation, which are only relevant for coronals.

The features [son] [cont] and [cons] hold a controversial status in feature theory. Gnanadesikan (1997) has previously proposed to eliminate [sonorant] and [continuant] and replace them with a consonantal stricture scale. In feature geometry [sonorant] is treated as part of the Root node, due in part to its failure to spread in local assimilations, thus setting it apart from other features that do assimilate (McCarthy 1988). The feature [consonantal], also part of the Root node, has been rejected by Hume \& Odden (1996). Kirchner (1998) has convincingly argued against former analyses of lenition in which [continuant] could spread from vowels or continuant sonorants. Finally, Padgett (1995b) argued that [cont] was dependent on each place feature, essentially because local place assimilations must also refer to [cont]. Evidence suggests that the features [son] and [cont] are utilized for classificatory purposes only, and do not enter into local assimilations or distant agreements. In other words, they are not 'active' in the same sense as features such as [nasal] or [voice], which may spread locally and be involved in LDAC. These 'passive' features are used to classify segments according to natural classes only. The major Place nodes, Labial, Dorsal, Coronal and Pharyngeal ${ }^{9}$ also do not show long-distance agreement. We discuss possible reasons for their exclusion in $\$ 7$.

In summary, our cross-linguistic typology reveals several different types of LDAC. In each case, only segments that are highly similar interact. For those features that cross-cut different places of articulation, such as [nasal], [voice] and the laryngeal features, similarity is based on a degree of sonority, determined by shared properties of [sonorant] and [continuant]. The feature [voice] may also be required to match. Homorganicity is an additional similarity criterion that may be imposed on long-distance agreement involving these features. Coronal agreement is of a slightly different nature, and pertains only to subclasses of coronal segments. Similarity follows from the nature of the feature involved, tongue tip constriction area/orientation, which is relevant only for coronals. Deciding whether coronal agreement is LDAC or iterative local spreading is not always clear. This issue is examined in $\S 6$.

3.2 THE BASIS FOR AGREEMENT. Our cross-linguistic typology reveals a correlation between LDAC and similarity between the agreeing consonants. We view this correlation as key and propose that similarity forms the basis for establishing a relation between the interacting segments (building on Walker 1999, 2000a,b).

The formation of connections between similar segments is supported by research in the processing of phonological structure. Psycholinguistic studies reveal that the production of a given consonant primes or activates other consonants in the word that share a large number of features. The effects are apparent in speech errors where consonants that are near-identical are found to be more likely to participate in a slip of the tongue than ones that are less similar (Nooteboom 1967, MacKay 1970, Fromkin 1971, Shattuck-Hufnagel \& Klatt 1979, Kupin 1982, Stemberger 1982, Frisch 1996). It is observed that near-identical sounds often shift to identical ones. Representative examples include mispronunciation of the phrase subjects show as shubjects show (ShattuckHufnagel \& Klatt 1979), and misproducing yellow in the tongue twister red lorry, yellow lorry as yerow or yeyow. A kinematic study by Pouplier et al. (1999) finds evidence that errors can occur at the gestural level. Interpreting their findings in terms of features-the correlates of gestures in

9 We have also found no cases of LDAC involving the feature [retracted tongue root], which characterizes pharyngeals and uvulars. If this is the feature used in emphasis harmony (e.g. Davis 1995) or faucal harmony (Bessell 1992, 1998), it primarily affects vowels or spreads to all segments in a given domain. 
our framework - this study reveals that in some cases an individual feature may be mistakenly repeated in a similar segment while another feature does not carry over. Pouplier et al. note that in some instances, gestural level errors are not audibly perceptible, which is undoubtedly connected to errors of this sort being under-reported in early research on speech errors. Note also related findings by Mowrey \& MacKay (1970) and Frisch \& Wright (1996-1997). Other work with a perceptual focus finds that gradient perceived similarity is a factor that can contribute to the potential for interaction between segments, e.g. in calculating MSCs, as mentioned above (Frisch 1996, Frisch et al. 1997, MacEachern 1997[1999]).

In the aggregate, this research suggests that the occurrence of similar but different consonants in an utterance presents production and perception difficulties, a point that is addressed in spreading activation models of speech processing (Dell \& Reich 1980, Dell 1984, 1986, Stemberger 1985, MacKay 1987, among others). For our purposes, a key aspect of this modeling is that each of the featural properties of a consonant causes the associated processing nodes to become 'activated'. In a word containing two consonants that have only a small degree of difference, there is a significant overlap in the nodes that receive activation. The processing difficulty for consonants that are near-identical thus arises in coordinating their few separate features and keeping the similar segments distinct. As seen in the errors associated with tongue twisters, the tendency is to improve processing ease by overriding the differences between the consonants and making their properties match.

The interaction observed among near-identical sounds in processing provides support for the claim that speakers construct a grammaticized relation between similar segments. We note that this basis for interaction is not limited to consonants. Similar vowels are also observed to have increased likelihood of participation in speech errors (Shattuck-Hufnagel 1986), and a relation between vocalic segments might underlie certain vowel harmonies (cf. Krämer to appear). Moreover, similarity has been observed to form a basis for relations established between constituents at levels higher than the segment, for instance, between words (see Burzio 1999, 2000 on the notion of Gradient Attraction). We identify some additional cases in the next section.

3.3 THEORETICAL ASSUMPTIONS. We frame our analysis in Optimality Theory (OT; Prince \& Smolensky 1993) and adopt the Correspondence approach to faithfulness (McCarthy \& Prince 1995, 1999). We assume familiarity with the core assumptions of this framework.

As anticipated in $\$ 2.2$, we formalize the relation between consonants that interact in longdistance agreement in terms of correspondence. Following the definition given by McCarthy \& Prince (1995:262), two structures are in correspondence if a relation is established between their component elements. Correspondence constraints determine faithfulness of mapping between related structures by requiring identity of their structure and content. In general, we posit that similarity is a source of correspondence between structures, that is, structures that are recognized as alike in may ways are prone to be associated together, and this connection may be grammaticized in terms of a correspondence relation. Similarity may be morphological and/or phonological in basis, and we suggest that both kinds of similarity may contribute to the occurrence of correspondence between structures. Consider the familiar examples of correspondence between input-output, stem-affixed stem and base-reduplicant. The occurrence of a correspondence relation in the first two cases is attributable to the morphological similarity of the structures, and in the latter case it is the result of a morphological requirement that the reduplicant be phonologically similar to its base. In the case of LDAC, correspondence between consonants in the output is suggested to arise from their phonological similarity. Other studies have identified correspondence attributable to phonological similarity at higher levels of organization. On the basis of pseudo-reduplication phenomena, Zuraw (2000) has argued for a violable constraint which requires that syllables within the same word stand in correspondence, and research on onset- 
identity effects by Suzuki (1999) has found evidence for a constraint requiring correspondence between the onsets of adjacent syllables. Within the theory at large, our proposal also connects to a broad range of other research identifying linguistic requirements that phonological elements in a word be repeated or copied outside of morphological reduplication (see Goad 1996, Yip 1997, MacEachern 1997[1999], Rose 1997, Kitto \& De Lacy 1999, Ussishkin 1999, Krämer to appear).

The requirement that correspondence be established between similar consonants in the output is expressed as a violable constraint, after Walker (1999). The schema for this type of constraint is given in (17), generalized over all consonants.

Corr- $\mathrm{C} \leftrightarrow \mathrm{C}$

Let $S$ be an output string of segments. If consonants $C_{i}, C_{j} \in S$, then $C_{i}$ is in a relation with $C_{j}$, that is, $C_{i}$ and $C_{j}$ are correspondents of one another.

We have determined that similarity is an important factor in activating a correspondence relation between consonants. Accordingly, we posit that CORR-C $\leftrightarrow \mathrm{C}$ constraints hold specifically of pairs of similar consonants. To capture the gradient nature of similarity, we array the constraints in a fixed hierarchy such that the more similar the pair of consonants, the higher ranked the requirement that they correspond. To illustrate, the portion of the correspondence hierarchy relevant for voicing agreement among stops is given in (18) (drawing on Walker 2000a).

Similarity-based correspondence hierarchy :

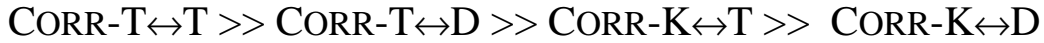

The constraints in (18) are interpreted as follows. CORR-T $\leftrightarrow \mathrm{T}$ requires that a correspondence relation be established between stops that agree in place and voicing (e.g. [...t...t...], [...b...b...]). CORR-T $\leftrightarrow \mathrm{D}$ expresses the same requirement for the superset of stop pairs that agree in place, i.e. pairs that are at least as similar as [t] and [d] (e.g. [...p...b...], [...d...t...], $[\ldots \mathrm{k} \ldots \mathrm{k} \ldots])$. CORR-K↔T encompasses any pair that agrees in voicing, including heterorganic pairs, and CORR-K↔D expands to any pair of oral stops. We suggest that correspondence constraints exist only for pairs of consonants that are above a certain threshold of similarity. The threshold could be determined numerically using a quantified measure of similarity. For the present study, we will use the cross-linguistic typology of long-distance agreement as a guide to the segment pairs that are sufficiently similar to trigger correspondence. On a related point, we note that the hierarchy in (18) is framed to facilitate discussion of similarity for the segments that are relevant to voicing agreement. However, it might well be subsumed under a more general hierarchy that expresses similarity in numeric terms rather than by specific segment groups. For example, the top-ranked CORR constraint would apply to any pair of segments that are maximally similar, the next one down would apply to those that are scaled as one unit less in similarity, and so on. Such numeric assessment has parallels in the sonority hierarchy (e.g. Steriade 1982, Selkirk 1984) and the impedance hierarchy (Hume \& Odden 1996). Like these other hierarchies, we do not base our scale on a simple feature count, but rather find that some features weigh more heavily than others in determining similarity.

A schema of the relevant correspondence relations that hold within a hypothetical form [bepo] is given in (19). Faith-IO constraints enforce faithfulness between the input and output forms. Within the output, CORR-C $\leftrightarrow \mathrm{C}$ constraints can produce correspondence between similar consonants. Faith-CC constraints require identity of structure and content between these segments. 
(19)

Consonantal correspondence model:

Input $/ \mathrm{b}$ e po/

Output [b e p o]

合㐁 CC Faithfulness

A Faith-CC constraint applicable to the property of voicing is given in (20). It requires that if a consonant in the output is specified as [voice], any corresponding Cs in the output must match in voicing specification. We assume that laryngeal features are monovalent, but the basic analysis is not altered if binary features are adopted instead.

IDENT-CC(voice)

Let $C_{i}$ be a consonant in the output and $C_{j}$ be any correspondent of $C_{i}$ in the output. If $C_{i}$ is [voice] then $\mathrm{C}_{\mathrm{j}}$ is [voice].

The constraint in (20) is formulated without reference to the ordering of the segments. However, the existence in some languages of unidirectional rightward or leftward LDAC agreement which is not derivative from morphological structure will necessitate an elaboration in directional terms, as discussed in $\S 4$.

Constraints enforcing faithfulness between input and output also play a key role. Drawing on a proposal by Pater (1999), we assume that IDENT constraints may distinguish between the loss or gain of privative feature specifications (an extension also adopted by McCarthy \& Prince 1995, 1999 with application to binary features). Examples are given in (21). IDENT-IO(voice) penalizes the loss of input [voice] specifications, and IDENT-OI(voice) punishes segments that acquire [voice] in the output.

\section{a. IDENT-IO(voice)}

Let $\alpha$ be a segment in the input and $\beta$ be any correspondent segment of $\alpha$ in the output. If $\alpha$ is [voice], then $\beta$ is [voice].

b. IDENT-OI(voice)

Let $\alpha$ be a segment in the input and $\beta$ be any correspondent segment of $\alpha$ in the output. If $\beta$ is [voice], then $\alpha$ is [voice].

We illustrate the evaluation of the above constraints with respect to an assortment of candidates in (22). This tableau simply tabulates violations; constraints are unranked here. Subscripted letters annotate $\mathrm{CC}$ correspondence. We assume that IO relations in the candidates shown here and in subsequent tableaux are such that segments with matching positions in the input and output strings are in correspondence.

(22) Correspondence among consonants in the output

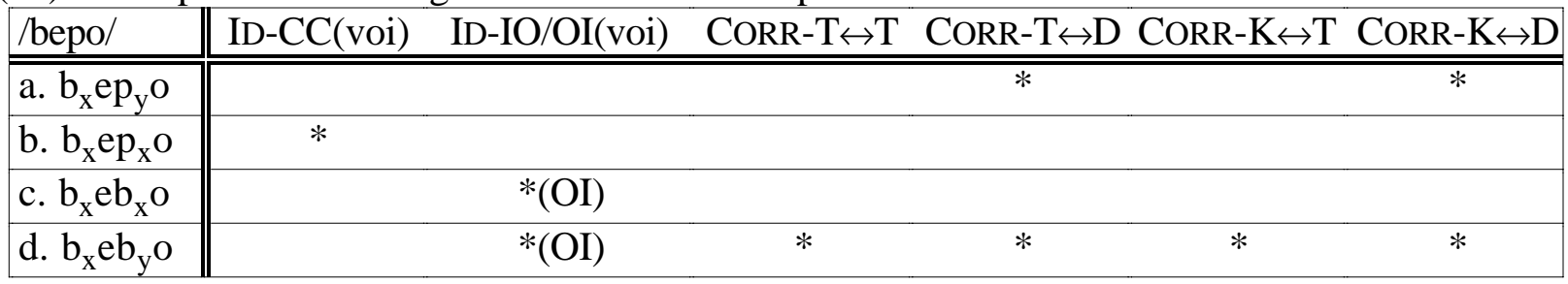

Candidates (22a-b) do not display voicing agreement. In (22a) the homorganic consonants are not in correspondence, violating Corr- $\mathrm{T} \leftrightarrow \mathrm{D}$, and by implication, Corr- $\mathrm{K} \leftrightarrow \mathrm{D}$, as well. In (22b), the 
consonants are in correspondence, but they do not agree for voicing, incurring a violation of IDENT-CC(voice). Candidate (22c) exemplifies the LDAC outcome. The consonants are in correspondence with each other and they agree in their voicing specification. Finally, candidate (22d) shows an instance of unmotivated change. Here the second consonant has become voiced, but without being in correspondence with the first consonant. This candidate is sub-optimal under any ranking of this set of constraints. ${ }^{10}$

In what follows we explore the application of the LDAC approach through two sets of case studies. The first considers nasal agreement in Ngbaka and Kikongo. These languages are distinguished by the point they select on the similarity scale to determine participants in agreement. They also illustrate how differences in the inventory can affect the set of interacting segments. The second pair investigates laryngeal agreement in Chaha and Bolivian Aymara. These languages also contrast in the strength of the similarity requirement that is enforced between agreeing segments. In Chaha we note the effect of a proximity tendency between agreeing segments and contrast LDAC with a separate local laryngeal spreading that is active in the language. Bolivian Aymara presents an intriguing conflict between a laryngeal OCP effect and laryngeal agreement.

\section{CASE STUDIES I: NASAL AGREEMENT}

4.1 DATA AND DESCRIPTION: NGBAKA AND KIKONGO. The first case of long-distance nasal agreement that we consider occurs in Ngbaka, a Niger-Congo language spoken in the Democratic Republic of the Congo (Thomas 1963). The consonant inventory of Ngbaka includes four series of stops on the nasality-voicing continuum: nasal, prenasal, voiced, and voiceless. The language displays restrictions on the combinations of homorganic consonants that may occur within a noncompound word (Sagey 1986, Mester 1986). We focus here on the restriction involving nasals, wherein nasal stops are excluded from occurring with homorganic prenasal stops. By contrast, pairs of homorganic nasals or homorganic prenasals (i.e. identical consonants) are permissible:

10 A conceivable alternative to the scaling of CORR-C $\leftrightarrow \mathrm{C}$ constraints would be to attempt to instead obtain similarity via a fixed ranking of IDENT constraints alongside an undifferentiated version of CORR-C $\leftrightarrow \mathrm{C}$. The faithbased hierarchy would be composed of simple IDENT-CC constraints as well as constraints formed by local conjunction (Smolensky 1993, 1997), such as IDENT-CC(voi) \& IDENT-CC(place): 'if in CC correspondence, do not disagree in voice and place', and IDENT-IO(voi) \& IDENT-CC(place): 'consonants in CC correspondence do not change input voice specification if disagree in place'.

Our initial observation is that while such an approach is logically possible, it is not favored simply by virtue of IDENT constraints performing the evaluation in place of CORR-C $\leftrightarrow \mathrm{C}$. Indeed, the task of determining similarity is not intrinsic to the labor performed by faithfulness. IDENT constraints check feature matching in related representations, but they do not calculate the relative similarity of representations. As discussed in $\$ 3.1 .2$, similarity is not determined by a simple count of the number of matching features-certain features contribute more to segment similarity than others. Hence, a similarity scaling is required whether it holds over CORR-C $\leftrightarrow \mathrm{C}$ constraints or faithfulness; utilizing a faith-based hierarchy does not achieve a simplification on this front.

The potential advantage to be gained here would be replacement of the scale in (18) with a single CORR-C $\leftrightarrow \mathrm{C}$ constraint. However, we deem this benefit fails to outweigh at least two serious drawbacks of the faith-based alternative. These are as follows. First, fixing a ranking over a set of faithfulness constraints would be highly unusual. The possibility of different rankings of these constraints in input-output, base-reduplicant and other domains is critical in obtaining different cross-linguistic patterns. Moreover, in studies of languages that display lexical strata with respect to phonological properties, Itô \& Mester $(1995,2000)$ suggest that there is a fixed hierarchy of markedness constraints against which faithfulness constraints can be re-ranked, not the reverse. Second, given factorial typology, a faith-based hierarchy predicts the possibility of languages in which substantially dissimilar segments display agreement, provided that more similar segments do as well. This prediction does not conform with our observation that LDAC interactions arise only between consonants above a certain threshold of similarity. It could be posited that a single CORR-C $\leftrightarrow \mathrm{C}$ constraint holds only over consonants exceeding some similarity threshold. However, the similarity calculation would then be duplicated in the grammar, since the scaling over faithfulness would still be required to achieve a similarity hierarchy. Given these considerations, we reject a faith-based scaling and opt for our implementation of the similarity hierarchy via CORR-C $\leftrightarrow \mathrm{C}$. 

a. naǹ̀
'today'
$* n a^{\mathrm{n}} \mathrm{d} \grave{\varepsilon}$
b. ${ }^{\mathrm{m}} \mathrm{b} \varepsilon \grave{\varepsilon}^{\mathrm{m}} \mathrm{b} \varepsilon$
'snail'
*mbeغ̀me

A sketch of the prohibited pairs of stops is given in (24). [n] represents a dorso-palatal stop.

Prohibited combinations (either order)

$$
*_{\mathrm{m}}-{ }^{\mathrm{m}} \mathrm{b} \quad *_{\mathrm{n}}-{ }^{\mathrm{n}} \mathrm{d} \quad *_{\mathrm{n}}-{ }^{\mathrm{n}} \mathrm{g} \quad *_{\mathrm{m}}-{ }^{\mathrm{nm}} \mathrm{gb}
$$

The generalization is that nasals are excluded in combination with homorganic stops that are adjacent in the nasality-voicing series, but identical nasal pairs are acceptable. In other words, nasal and prenasal stops that match in place must also agree in nasality. ${ }^{11}$ The nasal agreement is limited to (near)-identical stops. Accordingly, consonant pairs that are less similar can disagree in nasality, for instance, in homorganic pairs, a nasal can occur with an oral stop (25a), and in heterorganic pairs, a nasal can occur with a prenasal stop (25b). In addition, two heterorganic nasals or prenasals are acceptable $(25 \mathrm{c}-\mathrm{d})$.
a. boma 'how'
b. màngà 'net'
c. mini
'tongue'
d. 'gámba 'navvy'

An intriguing aspect of the Ngbaka data is that the nasal agreement operates between stops at a distance. Ngbaka permits only CV syllables (Sagey 1986:261), and vowels that intervene between agreeing consonants remain unaffected. It is also noteworthy that phonemic nasal vowels of the language do not trigger nasal agreement; they are found in combination with onset stops of any nasality-voicing quality: [nẽ] 'dew', [mbẽ] 'brown, dark', [gõ] 'tender', [tõ] 'to spit'.

A second example of long-distance nasal agreement is exemplified by Kikongo, a language spoken in the Democratic Republic of the Congo, discussed by Meinhof (1932), Dereau (1955), Webb (1965), Ao (1991), Odden (1994), Piggott (1996). The inventory of Kikongo differs from Ngbaka in distinguishing just three series of stops: nasal, voiced, and voiceless. As previewed in $\S 3.1$, a nasal stop in Kikongo induces nasalization of certain voiced consonants occurring at any distance to its right within the stem (root and suffixes). The data in (26) show three suffixes containing a consonant that is realized as [1] or [d] when the stem contains no nasal stop-it is realized as [d] before [i] and as [1] before other vowels. Apart from the [1/d] consonant, /d/ also exists as a separate phoneme in the language. When preceded by a nasal in the stem, [1/d] becomes [n]. The nasals of Kikongo are [m n]. Vowel quality in suffixes is sensitive to a height harmony.
a. m-bud-idi
'I hit'
'I washed'
tu-kin-ini
tu-nik-ini
n-tum-ini
'we planted'
futumuk-ini
leem-ene
'we ground'
'I sent'
'resuscitated (intr.)'
'shone'
b. m-bul-ulu n-suk-ulu
c. kutootila-ila
sakid-ila
'I was hit'
'I was washed'
ma-kin-unu
ma-nik-unu
'it was planted'
'it was ground'
'to harvest for'
kukin-ina
'to dance for'
'to congratulate for'
kudumuk-ina
kukin-is-ina
'to jump for'
kudumuk-is-ina
'to cause to dance for'
'to cause to jump for'

\footnotetext{
11 Sagey (1986) suggests that labiovelars in Ngbaka have a major Labial place specification and a minor Dorsal one. She posits that the homorganicity restriction is sensitive only to major place, thereby obtaining the interaction between labial-labiovelar pairs but not velar-labiovelar pairs.
} 
Observe that as in Ngbaka, Kikongo nasal agreement takes place between segments at a distance. The agreeing segments in Kikongo can be separated by multiple syllables, and intervening vowels and voiceless consonants are neutral.

The nasal agreement of Kikongo targets not only [1/d], but also voiced stops at all places of articulation. On the basis of a dictionary search, Piggott (1996) determines that the segments in question do not appear after nasals in a stem, in other words, the following distributional generalization holds: *[.. $\{\mathrm{m}, \mathrm{n}\} \ldots\{\mathrm{b}, \mathrm{d}, \mathrm{g}, \mathrm{l}\} \ldots]$ (see also Ao 1991:195-6, fn. 3). ${ }^{12}$

The phonotactics of Kikongo admit NC complexes that are composed of nasal and oral stop elements. Interestingly, these structures behave neutral in nasal agreement. They do not induce nasalization of voiced stops or sonorant consonants (27a), and they are transparent to nasal agreement between simple nasals and voiced stops / sonorant consonants (27b).

$\begin{array}{ll}\text { a. kamb-ila } & \text { 'to intercept' } \\ \text { somp-ela } & \text { 'to borrow from/for' } \\ \text { bind-ula } & \text { 'to unlock' } \\ \text { kunt-ila } & \text { 'shake for' } \\ \text { tu-bing-idi } & \text { 'we hunted' } \\ \text { koyk-ela } & \text { 'to push to' }\end{array}$
b. tu-meng-ini 'we hated' tu-meng-ono 'we were hated' tu-mant-ini 'we climbed' wu-mant-unu 'it was climbed

4.1.1 'PRENASALIZED' NCs. The different behavior of Kikongo NC complexes versus the prenasal stops of Ngbaka presents an intriguing contrast. We suggest that this difference stems from a structural distinction for prenasals in these languages. Research on 'prenasalized' NCs converges on support for two main phonological structure types: (i) a two-root nasal-oral stop sequence, and (ii) a stop with a single root node and no phonological specification for [nasal]. We diagnose the former structure in Kikongo and the latter in Ngbaka, and our analysis of nasal agreement links this contrast to their divergent outcomes.

The position that NCs in which nasalization is phonologically active have a two-root structure, as in (28), is convincingly argued for by Padgett (1995b), building on Feinstein (1979). ${ }^{13}$ The special character of NCs is attributed to their ability to form a syllable onset in some languages.

$$
\begin{aligned}
& \text { m b } \\
& \text { Rt Rt } \\
& \text { / I / } \\
& \text { [nasal] Place }
\end{aligned}
$$

Studies of various Bantu languages contribute to the claim that prenasalized NCs are composed of two segments. For example, it has been argued that prenasalized NCs in Luganda and Kikuyu are

12 Piggott claims that Kikongo actually targets all voiced consonants in the language, adding [v, z, y] to the list. This assertion is based on his search of dictionary entries in Bentley (1887) and Laman (1936). However, Meinhof's (1932) description of Kikongo written in collaboration with Laman shows that is not the case. Nasal agreement can take place across a neutral [z], as in [van-uzuna] 'give again and again' and [son-uzuna] 'write again and again'. Compare [kamb-uzula] 'tell over and over again' where the target consonant is realized as [1] when the conditions for nasal agreement are not present (we will see presently that NC clusters do not trigger nasal agreement). In the case of [y], it appears that the status of this phoneme is tenuous. In the central dialects dealt with by Meinhof, the velar fricative appears to have often developed into the glide [j], and it is elided between vowels. Webb (1965) also reports finding no $[\gamma]$ in the Kindibu dialect. We were unable to find data to confirm or deny the targeting of [v]. Given the patterning of other sounds in the language, we posit that if this sound is neutral it has the phonological status of a fricative in the language, and if it is targeted, it is grouped with the approximants as [v].

${ }_{13}$ The aperture-theoretic approach to prenasalization proposed by Steriade (1993) makes related insights, though with a somewhat different view of what constitutes a root. 
demonstrably clusters underlyingly (Clements 1986, Herbert 1986). Also, the presence of a [nasal] feature is verified by $\mathrm{NC}$ triggering phonological vowel nasalization in some Bantu languages. This and further evidence is comprehensively reviewed by Padgett (1995b) and Piggott (1996).

Various properties of prenasalized NCs in Kikongo support the two-root structure in this language. First, the potential for disagreement in voicing between the elements of an NC complex is indicative of a two-root structure. Second, NCs present a more limited distribution than stops unambiguously composed of a single root. Simple nasal and oral stops occur both initially and medially in stems. By contrast, NC complexes occur stem-medially but are rare in the initial position of stems - they are generally found initially only when a preceding nasal is present via prefixation (Meinhof 1932:175). This distributional gap for $\mathrm{NC}$ is unexpected if it consists of a single segment. A third argument comes in our analysis of Kikongo nasal agreement below, wherein we connect the neutrality of NC complexes to their two-root representation. We are not unique in positing that Kikongo NCs consist of a segment sequence: several analysts who have addressed the structure of NC in Bantu languages with long-distance nasal agreement concur with a dual representation. Ao (1991) and Piggott (1996) posit nasal-oral stop sequences for Kikongo, and likewise Van den Eynde (1968:6) and Walker (2000b) for Yaka (note also Kidima 1991:4).

In contrast to Kikongo, the prenasalized stops in Ngbaka are uncontroversially segments with a single root (Thomas 1963, 1970, Mester 1986, Sagey 1986). As expected, they occur freely in both initial and medial positions:

$$
\begin{array}{llll}
\text { mbo } & \text { 'small' } & \mathrm{k} 0^{\mathrm{n}} \mathrm{d} \grave{\varepsilon} & \text { 'heart' } \\
\mathrm{n} \mathrm{da} & \text { 'place' } & \text { lòngò } & \text { 'elephant trap' }
\end{array}
$$

Although prenasal stops in Ngbaka are produced with a phase of nasalization, this realization does not imply the presence of [nasal] in their phonological structure. The existence of monosegmental stops that are phonetically realized as prenasal but have no phonological specification for [nasal] has been confirmed in several languages, including Barasano (Piggott 1992, Rice 1993) and Mixtec (Iverson \& Salmons 1996). Given that we have found no indication that nasality is phonologically active in the prenasalized stops of Ngbaka, we posit they are also members of this group. Following Rice we assume that the 'sonorant-obstruent' status of these stops distinguishes them from the plain voiced series, as determined by the presence of a spontanous voicing node in their structure.

We conclude that with respect to the nasality-voicing continuum, Ngbaka distinguishes four series of stops and Kikongo three, as shown in (30) for bilabials.

$$
\begin{array}{ll}
\text { Ngbaka: Four stop series } & \text { Kikongo: Three stop series } \\
p-b-{ }^{m} b-m & p-b-m
\end{array}
$$

4.1.2 SUMMARY. Let us review the main properties of Ngbaka and Kikongo nasal agreement. The patterns present the two primary characteristics of LDAC identified in \$3.1: the potential for non-local interactions, and a similarity effect. Evidence for the first property is abundant: the agreeing consonants need not be root-adjacent, and intervening segments, such as vowels, voiceless consonants and voiced fricatives, can occur without participating in or blocking the nasal agreement.

Turning to the similarity effect, the preferential targeting of similar segments is evident from nasalization in both languages affecting the series of stops that is closest to the nasals. Ngbaka levies a stricter requirement of similarity, limiting agreement to stops of the adjacent series that are homorganic with the nasal. Kikongo targets all stops in the adjacent series as well as approximant consonants that also share some properties with nasals. Classes of sounds that are substantially different from nasal stops do not enter into nasal agreement with them. Walker (2000b) points out 
that the basis for determining similarity to nasals lies in articulatory and auditory/acoustic properties. Voiced oral stops are similar to nasals in their articulatory configuration. They also share the acoustic correlates of voicing and produce similar transitions in the formant structures of neighboring vowels. This closeness is reflected in the consonant mutation of Modern Irish known as eclipsis, wherein voiced stops shift to nasals and voiceless obstruents shift to voiced (Ní Chiosáin 1991). In the case of nasals and approximant consonants, their acoustic properties are similar in their intensity and in displaying well-defined formants. This similarity has also been observed to trigger phonological interactions in other languages. For example, Flemming (1995a) suggests that the auditory closeness between [1] and [n] induces the substitution of [n] for $/ 1 /$ in fortition environments in Korean and Cuna. The resulting similarity scaling relevant for Kikongo, is shown in (31) and is consistent with the trends outlined in $\S 3.1$.

(31) Nasal similarity scale

Vocoid Approximant Cons. $\quad \Leftarrow$ Nasal Stop $\Rightarrow \quad$ Voiced Stop Voiced Fric., Voiceless Cons.

In Ngbaka, the stricter similarity effect along with the inclusion of a series of prenasal stops in the inventory limits nasal agreement to targets that are homorganic and prenasal.

4.2 ANALYSIS. The preceding discussion supports the following hierarchy for correspondence between nasals and other consonants. (' $\mathrm{L}$ ' represents an approximant consonant.)

(32) Nasal correspondence hierarchy:

CORR-N $\leftrightarrow \mathrm{N}>>$ CORR-M $\leftrightarrow \mathrm{N}, \mathrm{CORR}-\mathrm{N} \leftrightarrow{ }^{\mathrm{N}} \mathrm{D}>>$ CORR $-\mathrm{N} \leftrightarrow{ }^{\mathrm{M}} \mathrm{B}, \mathrm{CORR}-\mathrm{N} \leftrightarrow \mathrm{D}>>$

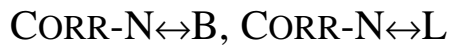

This hierarchy encodes that a pair of identical nasals is more similar than a homorganic nasal/ prenasal pair, which is in turn more similar than a pair comprised of a heterorganic nasal/prenasal or a homorganic nasal and voiced oral stop, and so on. Our data do not determine a ranking between CORR-M $\leftrightarrow \mathrm{N}$ and CORR-N $\leftrightarrow^{\mathrm{N}} \mathrm{D}$, so we have situated them together. The nasal correspondence hierarchy remains fixed across languages. We will argue that what distinguishes the patterns of nasal agreement in Ngbaka and Kikongo is the ranking of faithfulness with respect to the hierarchy in (32). The differences that we have identified in the inventory structure of the two languages will also have ramifications.

In our analysis, we will assume that [nasal] is a privative feature, given the observation that the feature specification [-nasal] does not appear to be active in assimilation or dissimilation phenomena (Trigo 1993, Steriade 1993, 1995). This choice is not crucial to our account, however. As discussed in $\$ 3.3$ with respect to [voice], we will require IDENT-IO(nasal), which is violated by the loss of an input [nasal] specification, and IDENT-OI(nasal), which penalizes segments that gain [nasal] in the output. Since alternations in Kikongo produce structures in which an output segment acquires nasalization, but denasalization of a nasal trigger does not occur, we posit the ranking IDENT-IO(nas) >> IDENT-OI(nas). Though alternations are not observed in Ngbaka, we will assume that the same ranking holds for this language. In what follows we will accordingly omit candidates involving denasalization from consideration.

4.2.1 HOMORGANIC NASAL AGREEMENT. We focus first on the rankings for Ngbaka. In this language, prenasal stops display nasal agreement with a homorganic nasal. Since prenasal stops in Ngbaka do not have a phonological [nasal] specification, the constraint demanding identity between corresponding stops must thereby override IDENT-OI(nas). The ranking is illustrated in (33) in relation to a hypothetical input. We interpret IDENT-CC(nas) as requiring that if a consonant $\mathrm{C}_{\mathrm{i}}$ in the output is [nasal], then any correspondent $\mathrm{C}_{\mathrm{j}}$ of $\mathrm{C}_{\mathrm{i}}$ in the output must also be [nasal]. (An 
elaboration of IDENT-CC that discriminates between left and right direction of evaluation is discussed in the Kikongo analysis.)

(33) IDENT-CC(nas) >> IDENT-OI(nas)

\begin{tabular}{|l||c|c|}
\hline$/ \mathrm{na}^{\mathrm{n}} \mathrm{d} \varepsilon /$ & ID-CC(nas) & ID-OI(nas) \\
\hline \hline a. $\mathrm{n}_{\mathrm{x}} \mathrm{an}_{\mathrm{x}} \varepsilon$ & & $*$ \\
\hline b. $\quad \mathrm{n}_{\mathrm{x}} \mathrm{a}^{\mathrm{n}} \mathrm{d}_{\mathrm{x}} \varepsilon$ & $* !$ & \\
\hline
\end{tabular}

In order to compel a correspondence relation between homorganic nasal and prenasal stops in the output, CORR-N $\leftrightarrow^{\mathrm{N}} \mathrm{D}$ must dominate IDENT-OI(nas), as shown in (34). The winning candidate is (34a), in which the stops are in correspondence and agree in nasality, incurring a violation of IDENT-OI(nas). The competitor in (34b) fails because the homorganic stops do not correspond. A third candidate in (34c) establishes correspondence between the stops, but loses on the basis of an IDENT-CC(nas) violation. IDENT-CC(nas) only crucially outranks IDENT-OI(nas) here, but since it is consistently obeyed in the language, we situate it at the top of the hierarchy.

(34) CORR-N $\leftrightarrow{ }^{N} \mathrm{D}>>$ IDENT-OI(nas)

\begin{tabular}{|l||c|c|c|c|c|}
\hline /na $\mathrm{n}^{\mathrm{n}} \mathrm{d} \varepsilon /$ & ID-CC(nas) & CORR-N $\leftrightarrow \mathrm{N}$ & CORR-M $\leftrightarrow \mathrm{N}$ & CORR-N ${ }^{\mathrm{N}} \mathrm{D}$ & ID-OI(nas) \\
\hline \hline a. $\mathrm{n}_{\mathrm{x}} \mathrm{an}_{\mathrm{x}} \varepsilon$ & & & & $*$ \\
\hline b. $\quad \mathrm{n}_{\mathrm{x}} \mathrm{a}^{\mathrm{n}} \mathrm{d}_{\mathrm{y}} \varepsilon$ & & & $* !$ & \\
\hline c. $\quad \mathrm{n}_{\mathrm{x}} \mathrm{a}^{\mathrm{n}} \mathrm{d}_{\mathrm{x}} \varepsilon$ & $* !$ & & & \\
\hline
\end{tabular}

Since nasal agreement is not enforced in heterorganic pairs, IDENT-OI(nas) must outrank CORR-N $\leftrightarrow{ }^{\mathrm{M}} \mathrm{B}$. The relevant set of candidates is seen in (35). The winning output in (35a) does not establish correspondence between the heterorganic nasal and prenasal consonants, violating CORR$\mathrm{N} \leftrightarrow{ }^{\mathrm{M}} \mathrm{B}$ but obeying IDENT-OI(nas). The alternatives in which the consonants correspond lose either because nasalization of the second stop violates IDENT-OI(nas) (35b) or because the corresponding stops do not agree in nasality (35c).

(35) IDENT-OI(nas) $>>$ CORR-N $\leftrightarrow{ }^{\mathrm{M}} \mathrm{B}$

\begin{tabular}{|c|c|c|c|c|}
\hline$/ \mathrm{ma}^{\mathrm{y}} \mathrm{ga} /$ & \begin{tabular}{|l|l} 
ID-CC(nas) & CORR-N $\leftrightarrow \mathrm{N}$ \\
\end{tabular} & \begin{tabular}{|l|l|} 
CORR-M $\leftrightarrow \mathrm{N}$ & CORR-N $\leftrightarrow{ }^{\mathrm{N}} \mathrm{D}$ \\
\end{tabular} & ID-OI(nas) & CORR-N $\leftrightarrow{ }^{\mathrm{M}} \mathrm{B}$ \\
\hline a. $m_{x} a^{y} g_{y} a$ & & & & 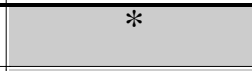 \\
\hline b. $m_{x} a n_{x} a$ & & & $* !$ & \\
\hline c. $\quad m_{x} a^{y} g_{x} a$ & $* !$ & & & \\
\hline
\end{tabular}

The lack of nasal agreement between nasal and voiced oral stop pairs is similarly captured via the ranking: IDENT-OI(nas) $>$ CORR-N $\leftrightarrow \mathrm{D}$.

A summary of the constraint ranking for the Ngbaka pattern of nasal agreement is given in (36). IDENT-OI(nas) is situated in the nasal correspondence hierarchy between CORR-N ${ }^{N} \mathrm{D}$, requiring correspondence between homorganic nasal and prenasal stops, and the CORR constraints that enforce correspondence between heterorganic nasal/prenasal stops and nasal/voiced oral stop pairs. IDENT-CC(nas), which promotes nasal identity between corresponding consonants, is undominated in this constraint group.

$$
\begin{array}{ll}
\text { Ngbaka: } & \text { ID-CC(nas), CORR-N } \leftrightarrow \mathrm{N}>>\text { CORR-M } \leftrightarrow \mathrm{N}, \text { CORR-N } \leftrightarrow{ }^{\mathrm{N}} \mathrm{D}>>\text { ID-OI(nas) }>> \\
& \text { CORR-N } \leftrightarrow{ }^{\mathrm{M}} \mathrm{B}, \mathrm{CORR}-\mathrm{N} \leftrightarrow \mathrm{D}
\end{array}
$$


4.2.2 HOMORGANIC AND HETERORGANIC NASAL AGREEMENT. We turn our attention now to Kikongo, where nasal agreement holds between nasals and voiced oral stops, both homorganic and heterorganic pairs. Approximant consonants also participate in nasal agreement.

Before advancing the details of the account, some preliminaries are in order. Since Kikongo does not include a series of prenasal stops in its inventory, the CORR-C $\leftrightarrow \mathrm{C}$ constraints involving prenasals will not be of direct relevance to the candidates that we consider. To simplify the presentation, we omit these constraints from the Kikongo tableaux. ${ }^{14}$ We also omit CORR-N↔N and CORR-M $\leftrightarrow \mathrm{N}$, since these constraints only produce redundant nasal agreement and will not play a critical role in the alternations we examine.

An interesting property of the Kikongo pattern of nasal agreement is its directionality. The rightward direction of agreement is exemplified in /kudumuk-ila/ $\rightarrow$ [kudumukina] *[kunumukina]. We propose that directional agreement arises from an evaluation of faithfulness sensitive to the left/right dimension. IDENT-CC constraints that distinguish progressive versus regressive agreement are given in (37). IDENT- $\mathrm{C}_{\mathrm{L}} \mathrm{C}_{\mathrm{R}}$ (nas) requires that if a consonant is [nasal], any corresponding consonant that appears to its right in the sequence of segments must also be [nasal], i.e. it compels nasal agreement in segments appearing to the right of a nasal. This constraint is silent on the reverse state of affairs: if an oral consonant appears to the left of a corresponding nasal, it is obeyed. IDENT- $\mathrm{C}_{\mathrm{R}} \mathrm{C}_{\mathrm{L}}$ (nas) is responsible for agreement in the leftward direction. Unidirectional agreement arises under asymmetrical rankings of directional IDENT-CC constraints. Prioritization of IDENT- $C_{L} C_{R}(F)$ will produce progressive feature agreement, as in Kikongo, and dominance of IDENT- $\mathrm{C}_{\mathrm{R}} \mathrm{C}_{\mathrm{L}}(\mathrm{F})$ will result in regressive agreement, as in Kinyarwanda sibilant harmony (see (11)). The left/right sensitive constraints can together replace the non-directional IDENT-CC(F). In a language such as Ngbaka, where there is no evidence of unidirectional agreement, both of these constraints are situated high.

a. IDENT- $\mathrm{C}_{\mathrm{L}} \mathrm{C}_{\mathrm{R}}$ (nas)

Let $C_{i}$ be a consonant in the output and $C_{j}$ be any correspondent of $C_{i}$ in the output such that $C_{j}$ follows $C_{i}$ in the sequence of segments in the output $(j>i)$. If $C_{i}$ is [nasal], then $\mathrm{C}_{\mathrm{j}}$ is [nasal].

b. IDENT- $\mathrm{C}_{\mathrm{R}} \mathrm{C}_{\mathrm{L}}$ (nas)

Let $\mathrm{C}_{\mathrm{i}}$ be a consonant in the output and $\mathrm{C}_{\mathrm{j}}$ be any correspondent of $\mathrm{C}_{\mathrm{i}}$ in the output such that $C_{j}$ follows $C_{i}$ in the sequence of segments in the output $(j>i)$. If $C_{j}$ is [nasal], then $C_{i}$ is [nasal].

Our account of unidirectional agreement calls on a distinction already available in the formalism of Correspondence Theory: for $\alpha \mathcal{R} \beta$, faithfulness constraints may target either $\alpha$ or $\beta$. In the case of input-output correspondence, examples of constraints that target $\alpha$ include the MAX-IO family (McCarthy \& Prince 1995) and the IDENT-IO formalism of Pater (1999), while those focusing on $\beta$ are DEP-IO constraints and IDENT-OI. The directional constraints in (37) similarly distinguish the target of faithfulness, with characterization of $\alpha$ and $\beta$ in terms of the precedence dimension.

To obtain the rightward nasal agreement in Kikongo, we posit the ranking: IDENT- $\mathrm{C}_{\mathrm{L}} \mathrm{C}_{\mathrm{R}}$ (nas) $>$ IDENT- $C_{R} C_{L}$ (nas). Since IDENT- $C_{L} C_{R}$ is always obeyed by the consonants that participate in Kikongo nasal agreement, we locate this constraint at the top of the hierarchy. The dominated status of IDENT- $C_{R} C_{L}$ will become apparent when we examine forms in which an oral voiced stop or approximant consonant precedes a nasal in a word.

First, we determine the ranking of IDENT-OI(nas) with respect to IDENT- $C_{L} C_{R}$ (nas) and the

14 Our omission of the prenasal correspondence constraints is simply an expositional convenience. It does not deny the universality of these constraints or their fixed place in the nasal correspondence hierarchy. 
nasal correspondence hierarchy. In Kikongo, any voiced stop becomes nasal if preceded by a nasal in the stem. This pattern signals that CORR-N↔B and IDENT- $C_{L} C_{R}($ nas) together outrank IDENT$\mathrm{OI}($ nas), as shown in (38). The winning candidate in (38a) establishes correspondence between the nasal and suffix consonant, and they agree for nasality in the output. ${ }^{15}$ In (38b), the stops do not correspond, incurring a fatal violation of CORR-N $\leftrightarrow B$, and in (38c) the stops correspond but do not agree in nasality, an outcome ruled out by IDENT- $\mathrm{C}_{\mathrm{L}} \mathrm{C}_{\mathrm{R}}\left(\right.$ nas). ${ }^{16}$

(38) IDENT- $\mathrm{C}_{\mathrm{L}} \mathrm{C}_{\mathrm{R}}$ (nas), CORR-N $\leftrightarrow \mathrm{B}>>$ IDENT-OI(nas)

\begin{tabular}{|c|c|c|c|c|}
\hline /tum-idi/ & $\mathrm{ID}_{\mathrm{L}} \mathrm{C}_{\mathrm{L}} \mathrm{C}_{\mathrm{R}}$ (nas) & CORR-N $\leftrightarrow \mathrm{D}$ & CORR-N $\leftrightarrow B$ & ID-OI(nas) \\
\hline a. $\operatorname{tum}_{x}$ in $_{x} i$ & & & & \\
\hline b. $\quad \operatorname{tum}_{\mathrm{x}} \mathrm{id}_{\mathrm{y}} \mathrm{i}$ & & & $* !$ & \\
\hline c. $\quad \operatorname{tum}_{x} \mathrm{id}_{\mathrm{x}} \mathrm{i}$ & $* !$ & & & \\
\hline
\end{tabular}

In addition to voiced stops, approximant consonants participate in Kikongo nasal agreement. This pattern is captured by situating IDENT-OI(nas) below CORR-N↔L as well. We tentatively locate CORR-N $\leftrightarrow \mathrm{L}$ and CORR-N $\leftrightarrow \mathrm{B}$ together in the nasal correspondence hierarchy. The outcome is illustrated in (39). Candidates (39b) and (39c), which do not nasalize /1/ in the output, are eliminated on the basis of CORR-N↔L and IDENT-CC(nas), respectively. ${ }^{17}$

(39) CORR-N $\leftrightarrow \mathrm{L}>>$ IDENT-OI(nas)

\begin{tabular}{|c|c|c|c|c|c|}
\hline /nik-ulu/ & ID-C $\mathrm{C}_{\mathrm{L}} \mathrm{C}_{\mathrm{R}}$ (nas) & CORR-N $\leftrightarrow \mathrm{D}$ & CORR-N $\leftrightarrow B$ & CORR-N↔L & ID-OI(nas) \\
\hline a. $\mathrm{n}_{\mathrm{x}} \mathrm{ikun} \mathrm{n}_{\mathrm{x}} \mathrm{u}$ & & & & & $\bar{*}$ \\
\hline b. $\quad \mathrm{n}_{\mathrm{x}} \mathrm{ikul}_{\mathrm{y}} \mathrm{u}$ & & & & $* !$ & \\
\hline c. $\quad \mathrm{n}_{\mathrm{x}} \mathrm{ikul} \mathrm{x}_{\mathrm{x}} \mathrm{u}$ & $* !$ & & & & \\
\hline
\end{tabular}

Observe that the voiceless stop in (39) does not participate in nasal agreement. This outcome follows from its lack of similarity to the nasal: the nasal and voiceless stop are not sufficiently similar to be subject to CORR-C $\leftrightarrow \mathrm{C}$ constraints, and hence a relation is not enforced between them. Candidates in which these consonants are in correspondence are screened out by faithfulness constraints: $\left[\mathrm{n}_{\mathrm{x}} \mathrm{in}_{\mathrm{x}} \mathrm{in} \mathrm{x} u\right.$ ] incurs a gratuitous violation of IDENT-OI(nas), and likewise $\left[\mathrm{n}_{\mathrm{x}} \mathrm{ik} \mathrm{k}_{\mathrm{x}} \mathrm{un} \mathrm{x}\right.$ ] with respect to IDENT-CC(nas). Correspondence between consonants in the output thus occurs only when compelled by similarity-driven constraints, and the neutrality of voiceless consonants (and vowels and voiced fricatives) follows straightforwardly.

The tableau in (40) addresses the case where the direction of agreement is apparent. Nasal

15 Whether we posit / $/$ or /d/ as the suffix consonant in the input does not figure here. Either way, the consonant will be realized as [d] before [i] if oral. We attribute this outcome to the activity of a contextual markedness constraint that we refer to descriptively as $*$ li.

16 Note that alternative candidates [tum $i_{x} d_{y} i$ ] and $\left[\operatorname{tum}_{x} i n_{x} d_{x} i\right.$, which transform the /d/ to prenasalized [nd], will be non-optimal because in addition to violating DEP-IO for the inserted [n], they do not fare better than candidates in (38) on either the CORR-C $\leftrightarrow \mathrm{C}$ constraints or IDENT- $\mathrm{C}_{\mathrm{L}} \mathrm{C}_{\mathrm{R}}$. The [d] remains in violation of one of these constraint types, as in $(38 \mathrm{~b}-\mathrm{c})$.

${ }_{17}$ We regard it as unsurprising that under nasal agreement the affected consonant becomes a plain nasal stop at the cost of manner features that might be active in the segment. For instance, when [1] becomes a nasal segment it does not retain its approximant nature (attributable to the feature [lateral]). In addition, there are no reports of nasal continuants in languages where continuant approximants are affected by nasal agreement in MSCs. The explanation here is two-fold. First, the dispreference for nasalized continuants/approximants is well documented (Padgett 1995b). Constraints on such configurations will trigger the hardening of approximants to stops under nasalization. Second, the formation of nasal stops rather than nasalized segments better satisfies IDENT-CC requirements. These constraints will promote the closest match in stricture and other properties between agreeing segments. 
agreement in this word produces nasalization only in the $/ 1 /$ to the right of the nasal and leaves the oral quality of the /d/ to its left intact. The resulting output sequence obeys IDENT- $_{L} C_{R}($ nas), which requires that corresponding consonants following a nasal be specified [nasal], but it violates IDENT- $\mathrm{C}_{\mathrm{R}} \mathrm{C}_{\mathrm{L}}$ (nas), which requires a [nasal] specification in corresponding consonants preceding a nasal. It is the interleaving of IDENT-OI(nas) between these two constraints that achieves unidirectional agreement. The ranking of IDENT- $\mathrm{C}_{\mathrm{L}} \mathrm{C}_{\mathrm{R}}$ (nas) over IDENT-OI(nas) compels rightward nasal agreement in the $/ 1 /$, as evident in the comparison of (40a) and (40f). The strict directionality is seen in the evaluation of (40a) versus (40b-c). First, in (40a) versus (b), both candidates establish correspondence between all three voiced consonants and both obey IDENT- $\mathrm{C}_{\mathrm{L}} \mathrm{C}_{\mathrm{R}}(\mathrm{nas})$. However, the leftward nasal agreement affecting the first voiced consonant in (40b) incurs a fatal violation of IDENT-OI(nas). Even though this candidate fares better with respect to IDENT$\mathrm{C}_{\mathrm{R}} \mathrm{C}_{\mathrm{L}}$ (nas), this constraint is dominated by IDENT-OI(nas), and hence the faithful mapping of the leftward /d/ is favored. Candidates (40a) and (c) incur equal violations with respect to IDENT$\mathrm{OI}($ nas), but (40c) violates CORR-N $\leftrightarrow \mathrm{L}$ while (40a) obeys it. Nasalization of the first voiced consonant is thus again disharmonic. CORR-C $\leftrightarrow \mathrm{C}$ constraints also serve to rule out candidates (40d) and (40e).

(40) IDENT- $\mathrm{C}_{\mathrm{L}} \mathrm{C}_{\mathrm{R}}$ (nas) $>>$ IDENT-OI(nas) $>>$ IDENT- $\mathrm{C}_{\mathrm{R}} \mathrm{C}_{\mathrm{L}}$ (nas)

\begin{tabular}{|c|c|c|c|c|c|c|}
\hline /kudumuk-ila/ & $\begin{array}{c}\text { ID-C } C_{L} C_{R} \\
\text { (nas) }\end{array}$ & $\begin{array}{c}\text { CORR- } \\
\mathrm{N} \leftrightarrow \mathrm{D}\end{array}$ & $\begin{array}{l}\text { CORR- } \\
\mathrm{N} \leftrightarrow \mathrm{B}\end{array}$ & $\begin{array}{l}\text { CORR- } \\
\mathrm{N} \leftrightarrow \mathrm{L}\end{array}$ & $\begin{array}{c}\text { ID-OI } \\
\text { (nas) }\end{array}$ & $\begin{array}{c}\text { ID- } \mathrm{C}_{\mathrm{R}} \mathrm{C}_{\mathrm{L}} \\
\text { (nas) }\end{array}$ \\
\hline a. $\operatorname{kud}_{\mathrm{x}} \mathrm{um}_{\mathrm{x}} \mathrm{ukin} \mathrm{x}_{\mathrm{x}} \mathrm{a}$ & & & & & $\bar{*}$ & $\overline{* *}$ \\
\hline b. $\operatorname{kun}_{\mathrm{x}} \mathrm{um}_{\mathrm{x}} \mathrm{ukin}_{\mathrm{x}} \mathrm{a}$ & & & & & $* * !$ & \\
\hline c. $\quad$ kun $_{\mathrm{x}} \mathrm{um}_{\mathrm{x}} \mathrm{ukil} \mathrm{y}_{\mathrm{y}} \mathrm{a}$ & & & & $* ! *$ & $*$ & \\
\hline d. $\quad \operatorname{kud}_{\mathrm{x}} \mathrm{um}_{\mathrm{y}} \mathrm{ukin} \mathrm{y}_{\mathrm{y}} \mathrm{a}$ & & $* !$ & $* *$ & & $*$ & \\
\hline e. $\operatorname{kud}_{\mathrm{x}} u m_{\mathrm{y}} u k i l_{\mathrm{x}} \mathrm{a}$ & & & $*(!)$ & $*(!)$ & & \\
\hline f. $\operatorname{kud}_{\mathrm{x}} \mathrm{um}_{\mathrm{x}} \mathrm{ukil}_{\mathrm{x}} \mathrm{a}$ & $* !$ & & & & & $*$ \\
\hline
\end{tabular}

The final point that we address in our analysis of Kikongo is the neutrality of NC clusters in nasal agreement. In initial NCs, the nasal derives from a prefix, which stands outside the stem domain where nasal agreement takes place. In the case of medial NCs, we suggest that these segments' lack of participation stems from their different structural role in comparison to singleton stops. The relevant difference may lie in syllabification, whereby medial NC clusters in Kikongo are syllabified across syllables in contrast to singleton stops that are wholly contained within onsets. In support of a heterosyllabic syllabification of medial NC sequences in Kikongo, Ao (1991:195, fn. 2) points out that nasals devoice before a voiceless C word initially, e.g. [nkosi] 'lion', but not word medially in normal rate speech, e.g. [zinkosi] 'lions'. He suggests that this contextual difference arises because nasal devoicing occurs only in tautosyllabic NC sequences, and the nasal in a medial NC sequence is syllabified with the preceding vowel. ${ }^{18}$ Under the codaonset structure, the place-linked heterosyllabic status of $\mathrm{NC}$ could prevent its interaction with singleton stops. ${ }^{19}$ The preference for a relation to be established between segments that have

18 It may be that nasals with place features linked to a following onset are the only possible codas in Kikongo. Such a restriction is not cross-linguistically uncommon (cf., for example, Japanese which admits only place-linked nasals and geminates in word-medial codas).

19 In considering a two root structure for Yaka, Hyman points out that since NC does not trigger vowel shortening in preceding vowels, it must be assumed that the nasal is non-moraic (1995:19-20). A conceivable alternative is to posit medial NC in Yaka (and Kikongo) as a cluster with both segments syllabified into an onset. Their neutrality could then be understood as a result of the difference in the structural role of the place-linked clusters versus simple onsets. However, the syllable structure account of nasal devoicing in Kikongo would be lost under this scenario. 
matching structural roles has support from psycholinguistic research: segments that have the same syllable position are more likely to participate in speech errors (Shattuck-Hufnagel 1983, 1987). The relevant constraint is given in (41), following McCarthy \& Prince (1993, 1994) (see Gafos 1996[1999], 1998, Suzuki 1999 for applications).

\section{ST-ROLE-CC}

Corresponding consonants must have the same structural role.

From a wider theoretical perspective, we take the neutrality of NC in Kikongo as evidence that phonological structure can be key in determining similarity between segments, and accordingly, it influences their potential to interact at a distance. The scenario is laid out in (42). ST-ROLE-CC dominates CORR-C $\leftrightarrow \mathrm{C}$ constraints so as to inhibit correspondence between similar consonants that have different structural roles. This ranking is responsible for eliminating candidates (42c) and (42d), where stops in the NC cluster - each with at least a portion of their content contained within a syllable coda - are in correspondence with simple onset stops (a mark is accrued for each consonant pair that violates ST-ROLE). Candidate (42d) also violates a constraint on geminate nasals, which do not appear in the inventory of the language (Laman 1936) ${ }^{20}$ Candidates (42a) and (42b) both establish correspondence strictly between the singleton onset stops, obeying STROLE. Candidate (42a) is optimal because it also obeys Ident- $\mathrm{C}_{\mathrm{L}} \mathrm{C}_{\mathrm{R}}($ nas).

(42) NC does not trigger or undergo nasal agreement

\begin{tabular}{|c|c|c|c|c|c|c|}
\hline /meng-idi/ & $\begin{array}{c}\mathrm{ID}^{\mathrm{C}} \mathrm{C}_{\mathrm{L}} \mathrm{C}_{\mathrm{R}} \\
\text { (nas) }\end{array}$ & $\begin{array}{c}\text { ST-ROLE- } \\
\text { CC } \\
\end{array}$ & $\begin{array}{l}\text { CORR- } \\
\mathrm{N} \leftrightarrow \mathrm{D}\end{array}$ & $\begin{array}{l}\text { CORR- } \\
\mathrm{N} \leftrightarrow \mathrm{B}\end{array}$ & $\begin{array}{c}\text { ID-OI } \\
\text { (nas) }\end{array}$ & $\begin{array}{c}\text { ID- } C_{R} C_{L} \\
\text { (nas) }\end{array}$ \\
\hline 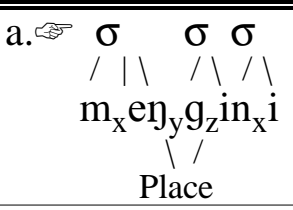 & & & * & "***** & * & \\
\hline b. \begin{tabular}{ccc}
$\sigma$ & $\sigma$ & $\sigma$ \\
$/ \mid$ & $/ 1$ & \multicolumn{1}{c}{} \\
$\mathrm{m}_{\mathrm{x}} \mathrm{en}_{\mathrm{y}} \mathrm{g}_{\mathrm{z}} \mathrm{id}_{\mathrm{x}} \mathrm{i}$ \\
$/ /$ \\
Place
\end{tabular} & $* !$ & & * & $* * * * *$ & & \\
\hline 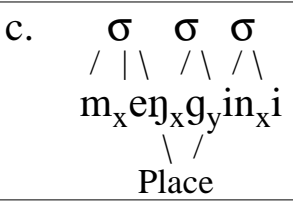 & & $* ! *$ & $*$ & $* * *$ & $*$ & \\
\hline 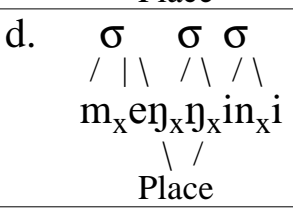 & & $* ! * * * *$ & & & $* *$ & \\
\hline
\end{tabular}

A summary of the constraint ranking determined for Kikongo is given in (43). We see here that IDENT-OI(nas) is located below the constraints enforcing correspondence between nasals / voiced stops and nasals / approximant consonants. The simple demotion of IDENT-OI(nas) in Kikongo in comparison to the Ngbaka ranking expands the set of segments participating in nasal agreement to include heterorganic stops and sonorant consonants.

20 A syllabic nasal prefix can occur before a stem-initial nasal in Kikongo to derive a heteromorphemic nasal cluster (Laman 1936). 


$$
\begin{aligned}
& \text { a. Kikongo: ID- } \mathrm{C}_{\mathrm{L}} \mathrm{C}_{\mathrm{R}} \text { (nas), ST-ROLE-CC }>\text { CORR-N↔N }>\text { CORR-M } \leftrightarrow \mathrm{N} \text {, CORR- } \\
& \mathrm{N} \leftrightarrow \mathrm{D} \gg>\text { CORR-N } \leftrightarrow \mathrm{B}, \text { CORR-N } \leftrightarrow \mathrm{L}>>\text { ID-OI(nas) } \gg>\text { ID- }_{\mathrm{R}} \mathrm{C}_{\mathrm{L}} \text { (nas) } \\
& \text { b. Ngbaka: ID-C } C_{I} C_{R} \text { (nas), ID- } C_{R} C_{L} \text { (nas), CORR-N } \leftrightarrow N \gg \text { CORR-M } \leftrightarrow N, \text { CORR-N } \leftrightarrow{ }^{N} D \\
& >\text { ID-OI(nas) }>\text { CORR-N } \leftrightarrow{ }^{\mathrm{M}} \mathrm{B}, \mathrm{CORR}-\mathrm{N} \leftrightarrow \mathrm{D}
\end{aligned}
$$

An additional point of contrast between Kikongo and Nbgaka is their inventory shape: Ngbaka includes a series of prenasal stops that are not found in Kikongo. Although the nasal-prenasal correspondence constraints are omitted for simplicity in (43a), the implications for a language with Ngbaka's inventory structure and Kikongo's ranking of IDENT-OI(nas) should be clear. If there were a language that had nasal, prenasal and voiced oral stop series, and nasal agreement included voiced oral stops, then prenasal stops would also participate in nasal agreement. In Kikongo, the neutrality of two-root prenasals provided evidence for the active role of ST-ROLE-CC in this language. In (43a) we place this constraint at the top of the hierarchy; however, we note that since CORR-N $\leftrightarrow \mathrm{N}$ and CORR-M $\leftrightarrow \mathrm{N}$ refer to consonants that already agree in nasality, the agreement pattern would not be altered if it were instead located below these constraints. Since Ngbaka lacks two-root prenasals, we do not have evidence for the placement of ST-ROLE-CC in its hierarchy.

Finally, the languages are distinguished by directionality of their agreement. In Kikongo, nasal agreement operates strictly to the right, as produced by the asymmetrical ranking of IDENT$\mathrm{C}_{\mathrm{L}} \mathrm{C}_{\mathrm{R}}$ (nas) and IDENT- $\mathrm{C}_{\mathrm{R}} \mathrm{C}_{\mathrm{L}}$ (nas). Ngbaka does not restrict agreement to a particular direction, which results from locating both of these constraints in the top stratum. In subsequent cases of agreement that we examine, we will show the leftward/rightward split for IDENT constraints only where there is evidence of unidirectionality. However, this presentational simplification does not deny that in such cases it is the two directional constraints ranked together in an upper level of the hierarchy.

4.3 SPREADING-BASED ALTERNATIVES. Previous accounts of long-distance nasal agreement assume a feature spreading approach. General drawbacks for admitting long-distance feature spreading in the theory were raised in $\$ 2.1$. We consider next some specific issues for feature spreading analyses of nasal agreement

In his study of Kikongo, Piggott (1996) makes the interesting proposal that long-distance nasal agreement results from a suprasegmental spreading, where [nasal] spreads at the level of a syllableorganizing node that he calls the harmony foot. The structure is illustrated in (44).

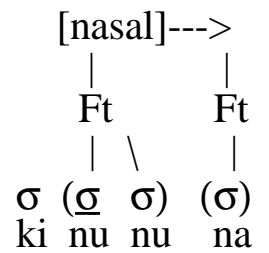

/kin-ulula/ -> [kinununa] 'to replant'

Under this approach, the oral quality of vowels within nasal harmony feet is attributed to the principle of Structure Preservation (Piggott 1996:155-6): since nasal vowels do not occur in any underlying representations, they are prevented from occurring in outputs. However, our typology reveals that long-distance agreement across languages preferentially targets sounds that are similar. ${ }^{21}$ Attributing the neutrality of vowels in nasal agreement to Structure Preservation misses this generalization. Indeed, nasal agreement in Ngbaka confirms that the explanation offered by

21 Cf. Dolbey \& Hansson (1999a,b), who hypothesize a historical impetus behind long distance nasal agreement in Bantu. 
Structure Preservation does not generalize across languages. Ngbaka has phonemic nasal vowels, but its vowels nevertheless pattern as neutral in nasal agreement. The similarity-based explanation that we advance here correctly predicts the preference for voiced consonant targets in LDAC with nasal stops as well as the neutrality of intervening non-participant segments. See Walker (2000b) on some additional issues for suprasegmental spreading with respect to constraining possible phonological structures.

An alternative spreading approach posits that [nasal] spreads at a subsegmental level, i.e. at a node contained within the root (Ao 1991, Odden 1994, Hyman 1995). Analyses of this kind have traditionally obtained the neutrality of intervening segments via their lack of target node or structure on the [nasal] tier. However, the underspecification or other structural inertness that must be assumed for neutral NC complexes is problematic. Consider the representation in (45), where NC is underspecified for [nasal] and its dominating node.

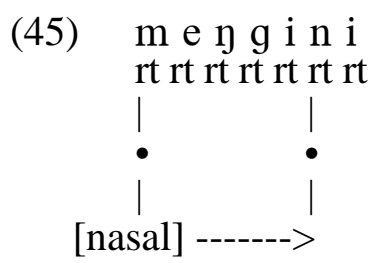

$$
\text { /meng-idi/ -> [mengini] 'we hated' }
$$

We must question why [nasal] and its dominating node would be underspecified in NC but not in singleton nasals and voiced stops. Hyman (1995) points out more generally that numerous ad hoc representational solutions are capable of producing the neutrality of NC. However, these representations fail to address why NC stands apart. By contrast, the correspondence approach connects the neutrality to the similarity effect. The structural difference between place-linked NC and monosegmental stops can prevent their interaction.

\section{CASE STUDIES II: LARYNGEAL AGREEMENT}

The features [spread glottis] and [constricted glottis] are grouped with [voice] to form the family of Laryngeal features. We have identified several cases of laryngeal agreement involving these features. In this section, we examine two languages in more detail. Chaha (Banksira 2000) has agreement effects in roots pertaining to both [cg] and [voice]. Bolivian Aymara (MacEachern 1997[1999]) shows agreement for [cg] and [sg] in roots. Other cases of voicing agreement include Ngbaka and Kera, which are analyzed in Walker (1999, 2000a).

5.1 CHAHA. Banksira (2000) reports that in Chaha, a Semitic Gurage dialect of Ethiopia, adjacent stops in a root may not differ in laryngeal specification. Stops will be either ejectives (46a) or voiced (46b). ${ }^{22}$ In general, the interacting stops are heterorganic, either coronal or velar. Due to Semitic morpheme structure constraints that prevent consonants of the same place of articulation from cooccurring in roots (Greenberg 1950, Buckley 1997), there are few instances of homorganic stops showing the agreement effect. We provide conjugations in the $3 \mathrm{~ms}$ imperfective and imperative to illustrate that different vowels may appear between the consonants.

22 These are given in the imperative and imperfective forms, as there is a morphologically-conditioned process that devoices penultimate obstruents in the perfective (normal citation form) if the following consonant is sonorant, [x] or [t], giving the surface appearance of a mix of voicing: e.g. [gidir] corresponds to perfective [gətərəm]. The devoicing effect does not extend to the initial consonant, suggesting that either voice agreement is not triggered by voiceless segments or the morphological devoicing requirement overrides agreement. 


\section{Imperfective Imperative}

$\begin{array}{lll}\text { a. } \text { ji-t'ək'ir } & \text { t'ik'ir } & \text { 'hide!' } \\ \text { ji-rət'ik' } & \text { nit'ik' } & \text { 'snatch' } \\ \text { ji-k'ət'ir } & \text { k'it'ir } & \text { 'kill!' } \\ \text { ji-rək'it' } & \text { nik'it' } & \text { 'kick!' } \\ \text { b. } \text { ji-dəg(i) } & \text { dig(i)s } & \text { 'give a feast!' } \\ \text { j-ad(i)g } & \text { əd(i)g } & \text { 'make fall!' } \\ \text { ji-gədir } & \text { gidir } & \text { 'put to sleep!' } \\ \text { j-ag(i)d } & \text { əg(i)d } & \text { 'tie!' }\end{array}$

The labial stops do not participate in the agreement, either as triggers or targets. Banksira (2000) argues that the only phonemic bilabials in Chaha are the sonorants $/ \mathrm{m} \beta /$. The voiced bilabial stop $[\mathrm{b}]$ occurs as an allophone of $/ \beta /$ in word-initial position, following nasals, and in certain morphologically-conditioned former gemination sites. The voiceless bilabial stop [p] only appears as a devoiced variant of this latter former geminate. Ejective [p'] does not occur except in a few loanwords from Amharic. The restriction of the agreement effect to coronals and velars is a result of the limited distribution of labial stops. We discuss this further below.

Banksira does not mention cases of voiceless stops adjacent to either ejectives or voiced stops, but we have found no examples of such roots in Banksira (2000), Leslau (1979) or other sources; adjacent plain voiceless stops $[\mathrm{k}]$ and $[\mathrm{t}]$ do cooccur: ${ }^{23}$
a. kitf
'hash (meat)!'
b. tiks
'set on fire!'
c. kətkit
'hit with a stick repeatedly!'

Fricatives are not targets of agreement (48a). As the inventory of fricatives is [ $\mathrm{f} \mathrm{s} \mathrm{z} \mathrm{x}$ ], /s/ could potentially be voiced to [z] by agreement. Fricatives and sonorants do not trigger agreement (48b):
a. sigd
'worship!'
$\operatorname{sidi} \beta$
'curse'
b. $\operatorname{kizə} \beta$
'become inferior!'
t'ima
'be thirsty!'

Banksira shows that Amharic cognates for many words have a combination of ejective and voiced consonants, where Chaha has matching laryngeal features. Note that the form [midad] is a case involving homorganic stops.

\begin{tabular}{|c|c|c|}
\hline Amharic & Chaha & \\
\hline$\underline{\text { k’ida }}$ & gida & 'draw liquid!' \\
\hline mit'ad & midad & 'griddle' \\
\hline dikk' ək' & t'ik' & 'be crushed, grounded!' \\
\hline wídək' & wit'ək' & 'fall!' \\
\hline t'ogar & digor & 'hair/animal hair' \\
\hline
\end{tabular}

We have found similar examples in related Gurage dialects which also show alternate [voice] or [cg] specification where Chaha has agreement, e.g. Endegen [dək'ək'ə] / Chaha [t'ək'ək'əm] 'be ground finely', Soddo [rəggət'ə] / Chaha [nək'ət'əm] 'kick' or Soddo [k'ədədə] / Chaha

23 Banksira (2000) argues that there is no underlying $/ \mathrm{k} /$, but $/ \mathrm{x} /$, which strengthens to $[\mathrm{k}]$ in certain circumstances, such as preceding fricatives. Indeed, [x] does cooccur with [d] in two verbs: [xəda] 'abjure, betray' or [xədərə] 'thatch a house'. But these same verbs are exceptional in that the second consonant does not devoice in the perfective form. 
[gədədəm] 'tear, make a hole' (Leslau 1979). In a few cases, agreement may operate across an intervening consonant: Soddo [dərrək'ə] / Chaha [t'ənək'əm] 'be dry' or Soddo [donk'ooro] / Chaha [t'onk' wara] 'deaf, stupid'. In other cases, agreement does not take place across intervening consonants: [t'əmədə] 'yoke' (cf. Muher [dəmədəm]), [dəfək'əm] 'scrub or pound laundry' or [dißak' ra] 'pumpkin' (cf. Endegen [t'aßak'ura]). There are also a couple of examples illustrating that agreement may be resisted across a vocalic root segment $/ \mathrm{j} \mathrm{w} /$, e.g. [tə-t $\int$ ' odəm] 'chat' < $/ \mathrm{t}$ ' $\mathrm{wd} /$, or root /a/, derived from a former pharyngeal or laryngeal consonant, e.g [gat'วm] 'nibble' or [dak'əm] 'laugh!' (see Banksira 2000, Chamora 1997, Lowenstamm 1996, Prunet 1996a,b, Rose 1997 on vocalic /a/ in Gurage languages). On the other hand, we also find agreement in such verbs, e.g. [a-k'et' $2 m$ ] < /k'yt'/ 'trade' most likely derived from Chara (Cushitic) [git'aa] 'trade' (Leslau 1979). Proximity can affect the strength of segment interaction in cases in which interaction is gradient. For example, Semitic root structure constraints on place of articulation are not absolute, and are weaker between consonants separated by another consonant than those adjacent (Greenberg 1950, Buckley 1997, McCarthy 1994, Pierrehumbert 1993, Frisch et al.1997).

We have found no examples of cognates in which a plain voiceless consonant $[\mathrm{t}]$ or $[\mathrm{k}]$ determines agreement. This has two possible explanations. First, [voice] may be a monovalent feature, and therefore [-voice] cannot trigger agreement (Lombardi 1991). In Chaha, the failure of plain voiceless stops to produce devoicing outcomes could accordingly be attributed to IDENT-IO(voi) >> IDENT-OI(voi) (cf. avoidance of denasalization in \$4.2). Second, there may be constraints in the other languages preventing voiced-voiceless or plain-glottalized stop combinations but allowing voiced-glottalized. Indeed, in the Gurage languages, we have found only a few examples of this former kind of mixture.

The restriction of [cg] agreement to stops is not surprising given that all ejectives in the language are stops. While [cg] may characterize fricatives, as in Amharic [s'], this segment is not present in Chaha. Nevertheless, the restriction of [voice] agreement to stops cannot be due to the absence of voiced fricatives. Chaha has a contrast between /s/ and /z/. Yet, as was illustrated in (48), [s] freely combines with voiced stops and [z] with voiceless stops. We find the same pattern of voice agreement being restricted to oral stops in the Chadic language, Kera (Walker 2000a). This is typical of LDAC in which participating segments are those that bear a high degree of similarity; in this case, the sub-class of stops among the larger class of obstruents.

5.1.1 ANALYSIS. As outlined in $\S 3.3$, similarity is calculated among stops based on a hierarchy of identical segments $(\mathrm{T} \leftrightarrow \mathrm{T})$, homorganic segments $(\mathrm{T} \leftrightarrow \mathrm{D})$, and heteroganic stops $(\mathrm{K} \leftrightarrow \mathrm{T}, \mathrm{K} \leftrightarrow \mathrm{D})$, as repeated from (18) in (50a) for voicing differences only. With [cg] adding another dimension, there are further correspondences between homorganic voiceless stops ( $\mathrm{T} \leftrightarrow \mathrm{T}^{\prime}$ ), heterorganic voiceless $\left(\mathrm{K} \leftrightarrow \mathrm{T}^{\prime}\right)$, homorganic $\left(\mathrm{D} \leftrightarrow \mathrm{T}^{\prime}\right)$ and heterorganic $\left(\mathrm{D} \leftrightarrow \mathrm{K}^{\prime}\right)$, as shown in (50b).

$$
\begin{array}{ll}
\text { a. } & \text { [voice] } \\
& \text { CORR-T } \leftrightarrow \mathrm{T}>>\text { CORR-T } \leftrightarrow \mathrm{D}>>\text { CORR-K } \leftrightarrow \mathrm{T}>>\text { CORR-K } \leftrightarrow \mathrm{D} \\
\text { b. } & {[\mathrm{cg}]} \\
& \text { CORR-T' } \leftrightarrow \mathrm{T}^{\prime}>>\text { CORR-T } \leftrightarrow \mathrm{T}^{\prime}>>\text { CORR-K } \leftrightarrow \mathrm{T}^{\prime}, \text { CORR-D } \leftrightarrow \mathrm{T}^{\prime}>>\text { CORR-D } \leftrightarrow \mathrm{K}^{\prime}
\end{array}
$$

The [voice] agreement hierarchy is familiar from §3.3. The [cg] constraints are interpreted as follows. CORR-T $\leftrightarrow \mathrm{T}$ ' requires correspondence between homorganic voiceless stops, including ejective and plain voiceless. CORR-K↔T' holds over the superset of homorganic and heterorganic voiceless stops. CORR-D $\leftrightarrow \mathrm{T}^{\prime}$ expands to include homorganic pairs that disagree in [voice] and [cg], and finally CORR-D $\leftrightarrow K^{\prime}$ refers to all stops, including those that disagree in laryngeal features. It is not clear if there is greater similarity between $\left[\mathrm{t}^{\prime}\right]$ and $[\mathrm{k}]$, which differ for Place and 
[cg] than between [t'] and [d], which differ for [voice] and [cg], so we have situated the constraints pertaining to these pairs of sounds at the same level in the correspondence hierarchy.

IDENT-CC requires that for the relation $\mathrm{C}_{\mathrm{i}} \mathcal{R} \mathrm{C}_{\mathrm{j}}$, if $\mathrm{C}_{\mathrm{i}}$ bears a particular laryngeal feature, then $\mathrm{C}_{\mathrm{j}}$ bears the same. IDENT-CC constraints are defined with respect to [voice] (see (20) from §3.3) and [cg]:

\section{IDENT-CC(cg)}

Let $\mathrm{C}_{\mathrm{i}}$ be a consonant in the output and $\mathrm{C}_{\mathrm{j}}$ be any correspondent of $\mathrm{C}_{\mathrm{i}}$ in the output. If $\mathrm{C}_{\mathrm{i}}$ is [cg] then $\mathrm{C}_{\mathrm{j}}$ is $[\mathrm{cg}]$.

As outlined in \$3.3, monovalent features entail the use of both IDENT-IO and IDENT-OI for [cg] and for [voice]. Since the Chaha pattern is consistent with conversion of voiced stops to ejectives and ejectives to voiced stops, we assume that both types of constraints will be low-ranked.

A correspondence relation is established between oral stops in a root, and the identity constraints require that they match for the features [voice] and [cg]. We illustrate the ranking for the stem [wit'ək'] 'fall!', for which we consider a possible input /widək'/ with a mix of a voiced stop and ejective. ${ }^{24}$ For reasons of space, we allow the capital letters $\mathrm{T}$ and $\mathrm{K}$ to stand for both ejectives and plain voiceless stops in the following tableau. Because laryngeal agreement includes all stops, including heterorganic pairs, the IDENT-IO/OI constraints are ranked below the CORR$\mathrm{K} \leftrightarrow \mathrm{D}$ constraint. Candidates (52b) and (52c) lose out to candidate (52a) because there is no correspondence relation established between the two stops in the root. Candidate (52d) loses to candidate (52a) because the corresponding stops do not match for [cg]. It is not enough that the consonants match only for [voice]. Finally, candidate (52e) shows that the IDENT-CC constraints must outrank the IDENT-IO/OI constraints in order to compel agreement.

(52) CORR-K↔D >> IDENT-IO/OI(cg), IDENT-IO/OI(voice),

\begin{tabular}{|c|c|c|c|c|c|c|c|c|}
\hline /wìdək'/ & $\begin{array}{c}\begin{array}{c}\text { ID-CC } \\
(\mathrm{cg})\end{array} \\
\end{array}$ & $\begin{array}{c}\text { ID-CC } \\
\text { (voi) } \\
\end{array}$ & $\begin{array}{c}\text { CORR- } \\
\mathrm{T} \leftrightarrow \mathrm{T} \\
\end{array}$ & $\begin{array}{c}\text { CORR- } \\
\mathrm{T} \leftrightarrow \mathrm{D} \\
\end{array}$ & $\begin{array}{c}\text { CORR- } \\
\mathrm{K} \leftrightarrow \mathrm{T} \\
\end{array}$ & $\begin{array}{c}\text { CORR- } \\
\mathrm{K} \leftrightarrow \mathrm{D} \\
\end{array}$ & $\begin{array}{c}\text { ID-IO/OI } \\
\text { (voi) } \\
\end{array}$ & $\begin{array}{c}\text { ID-IO/OI } \\
(\mathrm{cg}) \\
\end{array}$ \\
\hline a. wit' $_{\mathrm{x}} \partial \mathrm{k}_{\mathrm{x}}^{\prime}$ & & & & & & & $*(\mathrm{IO})$ & $*(\mathrm{OI})$ \\
\hline b. wit' ${ }_{\mathrm{x}} \partial \mathrm{k}_{\mathrm{y}}$ & & & & & $* !$ & $*$ & $*(\mathrm{IO})$ & $*(\mathrm{OI})$ \\
\hline c. $\quad \operatorname{wid}_{\mathrm{x}} \partial \mathrm{k}_{\mathrm{y}}^{\prime}$ & & & & & & $* !$ & & \\
\hline wit $_{x} \partial k_{x}^{\prime}$ & $* !$ & & & & & & $*(\mathrm{IO})$ & \\
\hline e. $\quad \operatorname{wid}_{\mathrm{x}} \partial \mathrm{k}_{\mathrm{x}}^{\prime}$ & $*(!)$ & $*(!)$ & & & & & & \\
\hline
\end{tabular}

The tableau in (52) illustrates an output with ejective agreement, reflecting the relationship between cognate Amharic [widək'] and Chaha [wit'ək']. However, it is also possible to derive a form with two voiced stops from a mixed ejective-voiced stop input. The choice of one versus the other would depend on directionality, which we ignore here in the synchronic grammar. The important point is that agreement for laryngeal features is enforced via CORR-C $\leftrightarrow \mathrm{C}$ at the expense of faithfulness.

We now consider the fate of the labial stops [b] and [p], which do not participate in agreement. As stated above, these stops are allophonic with $[\beta]$ and occur in restricted environments. To

24 Banksira (2000) points out that the cognate examples reveal that the laryngeal specification of the rightmost consonant determines the direction of agreement in Chaha. While this may have been the case diachronically, there is no evidence in the synchronic language for directionality, as the agreement pattern is restricted to roots. Accordingly, in our discussion of Chaha, we do not posit an asymmetrical ranking for directional IDENT-CC constraints, but note that dominance of the leftward constraint (IDENT- $C_{R} C_{L}(F)$ ) could be invoked. 
understand the distribution, some background on the history of the language is in order. The penultimate position of the perfective form of Chaha verbs was once geminate. ${ }^{25}$ As discovered by Banksira (2000), if the final root consonant was a sonorant or a plain voiceless stop, the penultimate (obstruent) geminate devoiced. If the final root consonant was a 'specified' obstruent, that is one with a Laryngeal specification ([sg] for fricatives, [cg] for ejectives and [voice] for voiced obstruents), no devoicing took place. Subsequently, geminates were reduced to singletons. ${ }^{26}$ The modern-day language now has voicing alternations within some paradigms such as [gətərəm] (perfective) vs. [jəgdir] (jussive) 'put to sleep'. The devoicing of the penultimate consonant does not carry over to other voiced stops in the stem. Other verbs show no alternation: [səgədəm]/[jəsgid] 'worship'. As for the labials, it is assumed that the sonorant $/ \beta /$ was realized as a geminate stop [bb]. The geminate /bb/ was devoiced to [pp] and reduced to a singleton. Besides a few loanwords, this is the only source of $[\mathrm{p}]$ in the language. Closely related dialects provide confirmation of this change. Compare the verb 'break' in three dialects: Ezha [səbbərəm], which has preserved gemination, Endegen [səppərəm] which has devoiced geminates, and Chaha [səpərəm]. The geminate [bb] was reduced to singleton [b] in those forms whose final consonant was a specified obstruent, such as [ $\left.\mathrm{t}^{\prime}\right]$ in the verb [t'əbət'วm], and this is preserved in modern-day Chaha. Disregarding a few loanwords, we have the following distribution of labial stops:

(53) $[\mathrm{p}] /$

in penultimate root position of perfective and other verb forms if following root segment is plain voiceless stop or sonorant;

[b] / word-initially;

post-nasal;

in penultimate root position of perfective and other verb forms if following root segment is obstruent other than $\left[\mathrm{t}([\mathrm{x}])^{27}\right]$

Labial stops cannot be targets of [cg] agreement since the ejective [p'] is not found in Chaha except in a few loanwords. A constraint preventing [p'] is undominated, ranked above the IDENT$\mathrm{CC}$ constraints. The voiceless stop [p] also cannot be a target of voice agreement due to its distribution. Since [p] only surfaces as a result of the morphologically-conditioned devoicing pattern outlined above, this means that it will never be followed by a voiced stop. Furthermore, [p] cannot be a target, since the devoicing pattern overrides surface agreement, as seen with examples such as [gətərəm]/[gidir]. Finally, the voiced stop [b] is not devoiced to [p] through agreement. It is devoiced only under the rubric of the morphological devoicing pattern. This indicates that the constraint(s) responsible for the morphological devoicing outrank *p which outranks the Ident-CC constraints. Furthermore, as mentioned previously we have no convincing evidence that voiceless stops can actually trigger agreement. Turning now to the potential for [b] to act as a trigger of voicing agreement, we note that $[\mathrm{b}]$ always alternates with [ $\beta]$ or [p] within a verbal paradigm. Examples are given in (54). In (54b), the / $\mathrm{r}$ / is realized as a nasal in the jussive, which assimilates for place of articulation to the following labial (a similar verb with no nasal alternation is shown in (54c) for comparison).

\footnotetext{
25 Other verb forms had geminates, such as imperfective of quadriliterals, imperfective of verbs with a /t-/ reflexive-passive prefix, and all forms of the lexical class 'Type B'. See Banksira (2000) for details.

26 Banksira (2000) posits synchronic underlying geminates which are neutralized to singletons by a degemination rule.

27 There is one verb with final [x]: [mesəxəm] 'chew' which Banksira assumes has a root /mzx/. However, due to its conjugation pattern, there are no [z]'s that show up in alternate forms, and one can only base the conclusion on related dialects, e.g. Ezha [məzzəxəm].
} 


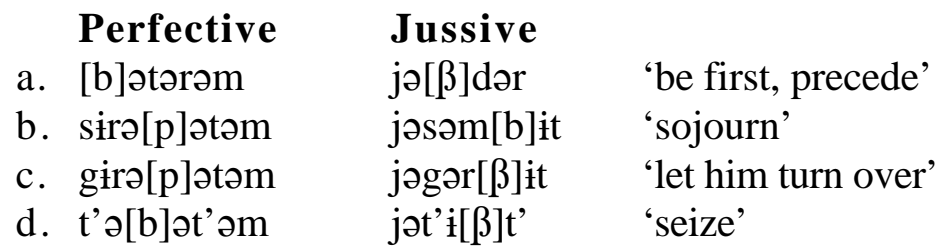

The only site where [b] has the potential to trigger voice agreement is when it is in the penultimate position of the perfective as in (54d), producing a hypothetical form such as * [dəbət'əm]. Such an alternation would render the paradigm non-uniform, since the $[b]$ is not found in the jussive, and only stops can trigger voice agreement. In all other cases of voice agreement, voicing is operative throughout the whole paradigm. We ascertain that paradigm uniformity prevents voicing from being triggered by penultimate $[\mathrm{b}]$. Although it is difficult to establish a definitive 'base' in Semitic upon which other words are based, we adopt the jussive/imperative form here since it is the least opaque of all Chaha stem forms in terms of consonant and vowel mutations (see Petros 1993 for a derivational analysis of Chaha verbs based on this assumption). There is a paradigmatic relation between the jussive base and the perfective mediated through output-output correspondence:

\section{IDENT-OO $(\mathrm{cg})$}

Let $\alpha$ be a segment in $S_{1}$ (jussive), and $\beta$ be a correspondent of $\alpha$ in $S_{2}$ (perfective). If $\alpha$ is $[\mathrm{cg}]$ then $\beta$ is $[\mathrm{cg}]$.

This constraint (and another pertaining to [voice]) outranks the constraints requiring identity between corresponding output segments. We show subscripts only for the first two stops. Conversion of the labial to either [p] or [p'] is banned by high-ranked markedness constraints, which we collapse here for the sake of space. The winning candidate is one which has no correspondence relation between the two stops.

(56)

\begin{tabular}{|c|c|c|c|c|c|c|c|c|}
\hline $\begin{array}{l}\text { /t'əbət'əm/ } \\
\text { base: t'i } \beta \text { t' }\end{array}$ & $* \mathrm{p}$ & $\begin{array}{c}\text { ID-OO } \\
(\mathrm{cg})\end{array}$ & $\begin{array}{c}\text { ID-CC } \\
(\mathrm{cg})\end{array}$ & $\begin{array}{c}\text { ID-CC } \\
\text { (voi) }\end{array}$ & $\begin{array}{c}\text { CORR- } \\
\mathrm{T} \leftrightarrow \mathrm{T}\end{array}$ & $\begin{array}{c}\text { CORR- } \\
\mathrm{T} \leftrightarrow \mathrm{D} \\
\end{array}$ & $\begin{array}{c}\text { CORR- } \\
\mathrm{K} \leftrightarrow \mathrm{T} \\
\end{array}$ & $\begin{array}{l}\text { CORR- } \\
\mathrm{K} \leftrightarrow \mathrm{D} \\
\end{array}$ \\
\hline a. $t_{x}^{\prime} \partial b_{y} \partial t^{\prime} \partial m$ & & & & & & & & * \\
\hline b. $t^{\prime}{ }_{x} \partial b_{x} \partial t^{\prime} \partial m$ & & & $*(!)$ & $*(!)$ & & & & \\
\hline c. $d_{x} \partial b_{x} \partial t^{\prime} \partial m$ & & $* !$ & & & & & & \\
\hline d. t' ${ }_{\mathrm{x}} \partial \mathrm{p}_{\mathrm{x}}{ }_{\mathrm{x}} \partial \mathrm{t}^{\prime} \partial \mathrm{m}$ & $* !$ & & & & & & & \\
\hline
\end{tabular}

The constraint(s) requiring morphological devoicing of the penultimate consonant in some forms outrank IDENT-OO(voice), allowing for a mismatch for [voice] in just those cases, but not as a result of agreement. In conclusion, agreement operates among oral stops, but the distribution of labial stops in the verb stem prevents them from participating.

5.1.2. PROXIMITY. Chaha agreement has a proximity effect, such that consonants that are adjacent in the morphological root agree for [voice] or [cg], but those that are further apart show less tendency to agree. Proximity is an independent requirement that may be imposed on elements interacting locally or at a distance. Odden (1994) identifies three major parameters of proximity or adjacency: root node adjacency, syllable adjacency and unbounded adjacency. Suzuki (1998) introduces a hierarchy that allows for other possibilities, such as separation by only a mora. Rose (2000) argues for another type, 'consonant adjacency', wherein consonants may interact only across an intervening vowel, either in the same or separate syllables. The proximity effect that 
Chaha exhibits is primarily this latter type, but some forms may show agreement at a greater distance.

Chaha is not alone in exhibiting a proximity effect on agreement. Other LDAC cases are subject to a proximity condition where only a vowel may separate the agreeing consonants. In Ndonga (Viljoen 1973), nasal agreement affects a suffixal /// when the target and trigger are in adjacent (open) syllables (57a). ${ }^{28}$ If separated by more than a vowel, nasal agreement does not obtain (57b).

$\begin{array}{ll}\text { a. monine } & \text { 'had seen' } \\ \text { tumine } & \text { 'had sent' } \\ \text { kunine } & \text { 'had sown' } \\ \text { limine } & \text { 'had ploughed' }\end{array}$
b. hulile 'had undressed' pepele 'had blown' minikile 'was looking for' jonagulile 'had damaged'

The same proximity restriction applies to nasal agreement in Lamba (Doke 1938, Odden 1994) and Bemba (author's fieldnotes).

Proximity is built into an OT analysis by parameterizing constraints for different proximity distances, following Suzuki (1998). For example a CORR-CC(Nasal) constraint would be subcategorized for allowing an intervening mora as in Ndonga or for no distance requirement $(\infty)$, as in Kikongo in \$4. According to Suzuki (1998), constraints subscripted for different elements are arrayed in a fixed proximity hierarchy, as shown in (58) for the CORR-CC constraints. ${ }^{29}$

\section{CORR-CC(Nasal) $\mu>>$ Corr-CC(Nasal $) \infty$}

IDENT-IO constraints would be ranked between the two constraints in (58) to capture Ndonga, but below them to account for Kikongo. Hence the proximity restriction that Chaha agreement exhibits is not unusual and can be handled by specifying the correspondence constraints for consonant adjacency.

It remains an open question whether local non-iterative root-adjacent assimilations are to be treated as assimilation through spreading or whether they might also be subject to an analysis incorporating agreement through correspondence. Both Odden (1994) and Suzuki (1998) recognize the root-adjacent parameter in determining proximity of interacting segments. The role of similarity appears to be key. While we do not rule out similarity as impacting the likelihood of segments to assimilate via feature spreading, it does not appear to be systematically implicated in the same way as agreement through correspondence demands. Local assimilation is often induced by phonotactic factors and coarticulation. For example, post-nasal voicing is the result of a coarticulation difficulty in terminating voicing following a nasal (Hayes \& Stivers 1995, Pater 1999). This does not apply in cases of long-distance interaction, and we find no cases of voicing agreement triggered by nasals. One possible solution to maintaining a dichotomy between local assimilation and LDAC would be to eliminate the root-adjacent option as a parameter of proximity and to recognize all local interactions as spreading. While there are reported cases of dissimilation subject to root-adjacency, many of them could also be reanalyzed as coarticulation or phonotactic pressures, such as constraints against gemination, or poor sonority sequencing. This would, of course, lead us beyond the scope of this paper, so we do not attempt to explore this possibility further here.

5.1.3 SPREADING VS. AGREEMENT. We compare the LDAC analysis of the Chaha data with three possible spreading/linkage analyses:

28 In Ndonga /1/ is the only coronal oral noncontinuant. [d] occurs in borrowings only.

29 Suzuki allows for many other possible intervening elements, which we ignore here. 
(59) a. Spreading/linkage at the morphological root level prior to affixation

b. Spreading at the surface skipping over vowels (gapped configuration)

c. Spreading through the vowel (local spreading)

The first analysis in (59a) involves a serial derivation in which features spread locally or are doubly linked at the level of the root prior to vowels combining with root consonants. This would require that MSCs be analyzed as involving double linking of features (Mester 1986, Yip 1989). Vowels break apart linked structure at a later stage in the derivation (e.g. McCarthy 1986). Once a vowel intervenes between the root consonants, there are therefore two possible outcomes: (i) a representation with two separate stops each specified for its own [cg] or [voice] feature, or (ii) a gapped configuration if the vowel is underspecified for [voice] or [cg], as shown in (60).

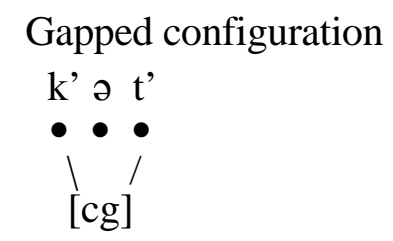

Once again, we have already addressed general problems with gapped configurations. But there are also problems with the mechanism that would lead to such a structure, or to one in which the consonants are separated. Several authors have argued that the separation of vowels and consonants onto separate autosegmental tiers followed by Tier Conflation is problematic in Semitic on various fronts (Bat-El 1988, Gafos 1996[1999], 1998, Rose 1997). Furthermore, it is not clear that vowels that are unspecified for a given feature actually succeed in splitting a linked structure (see Rose 1994 for discussion). Finally, separating consonants from vowels is not always sufficiently motivated for nominal forms that do not have templatic shapes, and we do find agreement occurring in nouns as well as verbs.

As discussed in $\$ 2.1$, a common thread emerging from recent studies is that a theory in which features link only between root-adjacent segments is more restrictive than one that allows gapped configurations (Padgett 1995a, Gafos 1996[1999], Walker 1998[2000], Ní Chiosáin \& Padgett to appear). These researchers propose analyses along the lines of (59c). Under such a proposal, a [cg] feature would be spread from one consonant to another in a continuous span and the intervening vowel would be phonetically affected by the $[\mathrm{cg}]$ feature:

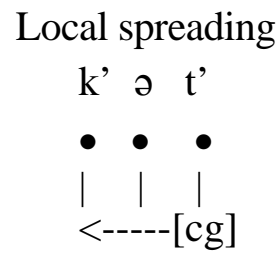

It is conceivable that glottalization of vowels may not be indicated in transcription if it is not contrastive. However, we examined spectrograms of Chaha vowels between two ejectives and found no solid evidence of continuous glottalization. Furthermore, no evidence of glottalization is found in forms with intervening sonorants, such as [t'ənək'əm] 'be dry'. In conclusion, all of these spreading analyses of long-distance laryngeal agreement prove to be problematic. Furthermore, support for an output-based correspondence analysis of agreement comes from the fact that we find similar laryngeal agreement patterns across vowels in other languages that do not have Semitic nonconcatenative morphology that would warrant the separation of vowels and consonants, as in Bolivian Aymara in the next section. 
Another argument in favor of voicing agreement through correspondence and against spreading of [voice] in roots is the restriction to stops. Patterns of local voicing assimilation crosslinguistically show two patterns: assimilation between all consonants including sonorants, or voicing assimilation only between obstruents (Lombardi 1991, Fallon 1998). We know of no cases in which local voicing assimilation is restricted to the sub-class of stops or the sub-class of fricatives. In Chaha, local voicing assimilation between adjacent segments occurs between all obstruents (Banksira 2000). The passive-reflexive prefix $/ \mathrm{t}-/$ in imperfective verb forms is optionally voiced before voiced obstruents, ${ }^{30}$ but not before sonorants. It is also optionally glottalized before ejectives.

\begin{tabular}{|c|c|c|c|}
\hline ji-t-gəməs & or & jì-d-gəməs & 'he cuts off into chunks' \\
\hline ji-t-zəməd & & ji-d-zəməd & 'he stretches (intr.)' \\
\hline ji-t-k'anəm & & jì-t'-k' anəm & 'he insults' \\
\hline ji-t-rək' ər & & *ji-d-rək'ər & 'it is uprooted' \\
\hline ji-t-manəx & & $* \mathrm{ji}-\mathrm{d}-\operatorname{man} ә \mathrm{x}$ & 'it is captured' \\
\hline
\end{tabular}

Crucially, the voicing assimilation shows no restriction to stops only. In addition, if a vowel intervenes, no voicing assimilation is attested. The /t-/ prefix of the verbs in (62) has an extra vowel, /tə-/ when attached to a perfective stem. Yet it is not realized with a voiced segment in this case: [tə-gəməsəm] 'he cut off into chunks' not *[də-gəməsəm]. As with [voice], local [cg] assimilation does not operate across a vowel: [tə-k'anəməm] 'he insulted' not *[t'ə-k'anəməm]. These data suggest that LDAC and local spreading of [voice] and [cg] are differentiated by the fact that local spreading may affect the whole class of obstruents, whereas LDAC is restricted to stops.

In conclusion, a correspondence analysis of [voice] and [cg] agreement in Chaha is superior to one involving spreading of these features. We now turn to another case of laryngeal agreement.

5.2 BoliviAn AYMARA. Bolivian Aymara ${ }^{31}$ (Davidson 1977, De Lucca 1987, Hardman et al., MacEachern 1996, 1997[1999]) has cooccurrence restrictions on both [cg] and [sg] in morphemes. Unlike Chaha, Bolivian Aymara imposes a homorganicity restriction on its agreement effect. Homorganic stops must agree for laryngeal features as shown in the following combinations. There are no voiced oral stops in the language. If heterorganic, stops may combine freely, except for ejectives, which must be identical to cooccur.

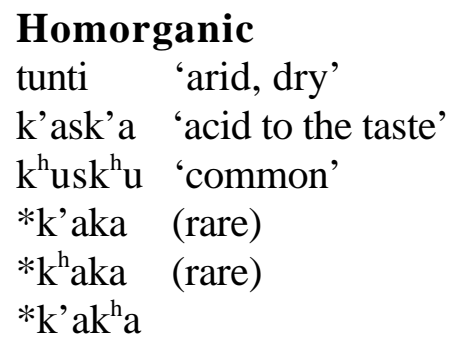

$\begin{array}{ll}\text { Heterorganic } & \\ \text { qotu } & \text { 'group, pile' } \\ \text { *t'ank'a } & \\ \text { p }^{\text {h}} \mathrm{t}^{\mathrm{h}} \mathrm{u} & \text { 'hole, hollow' } \\ \text { t'aqa } & \text { 'flock, herd' } \\ \mathrm{t}^{\mathrm{h}} \text { ampa } & \text { 'dense' } \\ \text { t'alp }^{\mathrm{h}} \mathrm{a} & \text { 'wide' }\end{array}$

5.2.1 BASIC ANALYSIS. We begin by illustrating the [sg] agreement effects. Stops must agree for spread glottis if homorganic. There is no agreement enforced if they are heterorganic. We assume the same basic hierarchy of CORR-CC constraints for [sg] as we did for [cg] in our analysis of Chaha. The faithfulness constraints IDENT-OI(sg) and IDENT-IO(sg) are ranked over

30 There is obligatory total assimilation before coronal stops and affricates: /ji-t-dəməd/ $\rightarrow$ [jiddəməd] 'he joins (intr.)'.

31 'Bolivian Aymara' is the term MacEachern uses to refer to the dialect of Aymara spoken primarily in Bolivia and described in De Lucca (1987). 
the correspondence constraint applicable to heterorganic, laryngeally non-identical stops, CORR$\mathrm{K}^{\mathrm{h}} \leftrightarrow \mathrm{T}$. This ranking effectively prevents altering the [sg] feature specification of the second consonant, as shown in (64).

(64) IDENT-IO(sg), IDENT-OI(sg) $>\mathrm{K}^{\mathrm{h}} \leftrightarrow \mathrm{T}$

\begin{tabular}{|c|c|c|c|c|c|c|}
\hline$/ \mathrm{t}^{\mathrm{h}} \mathrm{ampa} /$ & $\begin{array}{c}\text { ID-CC } \\
(\mathrm{sg})\end{array}$ & $\begin{array}{c}\text { CORR- } \\
\mathrm{K}^{\mathrm{h}} \leftrightarrow \mathrm{K}^{\mathrm{h}}\end{array}$ & $\begin{array}{l}\text { CORR- } \\
\mathrm{K}^{\mathrm{h}} \leftrightarrow \mathrm{K}\end{array}$ & ID-IO(sg) & ID-OI(sg) & $\begin{array}{l}\text { CORR- } \\
\mathrm{K}^{\mathrm{h} \leftrightarrow \mathrm{T}}\end{array}$ \\
\hline 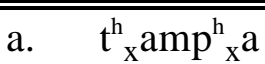 & & & & & $* !$ & \\
\hline b. $\mathrm{t}_{\mathrm{x}}^{\mathrm{h}} \mathrm{amp}_{\mathrm{y}} \mathrm{a}$ & & & & & & * \\
\hline c. $\quad \mathrm{t}_{\mathrm{x}}^{\mathrm{h}} \mathrm{amp}_{\mathrm{x}} \mathrm{a}$ & $* !$ & & & & & \\
\hline d. $t_{x} a m p p_{x} a$ & & & & $* !$ & & \\
\hline
\end{tabular}

If the input contained two aspirated stops, as in the word $\left[\mathrm{p}^{\mathrm{h}} \mathrm{u} \mathrm{t}^{\mathrm{h}} \mathrm{u}\right]$, then the constraint ranking would engender no alteration, because there are no high-ranking constraints compelling violations of input-output faithfulness.

In (65), we illustrate an example with homorganic stops and consider an input with only one aspirated stop. The constraint $\mathrm{K}^{\mathrm{h}} \leftrightarrow \mathrm{K}$ requires correspondence between any homorganic oral stops. By ranking this constraint above one of the input-output [sg] faithfulness constraints, agreement for [sg] is enforced. In the tableau given here, IDENT-IO(sg) is located above IDENT-OI(sg), which selects a winning candidate with double aspiration. However, the reverse ranking is equally possible and will favor a candidate with no aspiration. Both candidates (65a) and (65d) are wellformed roots; given that the agreement effect holds of roots and therefore shows no alternations, we cannot determine the exact ranking of the IDENT-IO/OI constraints. However, the point of this tableau is to illustrate that single aspiration candidates cannot emerge as winners even if they are entirely faithful to the input. In all future tableaux, we will arbitrarily rank IDENT-IO(sg) over IDENT-OI(sg) (and likewise for their (cg) counterparts), but note that the reverse is also possible.

(65) CORR-K $\mathrm{K}^{\mathrm{h}} \mathrm{K}>>$ either IDENT-OI(sg) or IDENT-IO(sg)

\begin{tabular}{|c|c|c|c|c|c|c|}
\hline$/ \mathrm{k}^{\mathrm{h}} \mathrm{usku} /$ & $\begin{array}{c}\text { ID-CC } \\
(\mathrm{sg})\end{array}$ & $\begin{array}{c}\text { CORR- } \\
\mathrm{K}^{\mathrm{h} \leftrightarrow \mathrm{K}^{\mathrm{h}}}\end{array}$ & $\begin{array}{l}\text { CORR- } \\
\mathrm{K}^{\mathrm{h} \leftrightarrow \mathrm{K}}\end{array}$ & ID-IO $(\mathrm{sg})$ & ID-OI(sg) & $\begin{array}{l}\text { CORR- } \\
\mathrm{K}^{\mathrm{h} \leftrightarrow \mathrm{T}}\end{array}$ \\
\hline a. $\mathrm{k}_{\mathrm{x}}^{\mathrm{h}} \mathrm{usk}_{\mathrm{x}}^{\mathrm{h}} \mathrm{u}$ & & & & & * & \\
\hline b. $\quad \mathrm{k}_{\mathrm{x}}^{\mathrm{h}} \mathrm{usk}_{\mathrm{y}} \mathrm{u}$ & & & $* !$ & & & * \\
\hline c. $\quad \mathrm{k}_{\mathrm{x}}^{\mathrm{h}} \mathrm{usk}_{\mathrm{x}} \mathrm{u}$ & $* !$ & & & & & \\
\hline d. $\quad \mathrm{k}_{\mathrm{x}} \mathrm{usk}_{\mathrm{x}} \mathrm{u}$ & & & & $* !$ & & \\
\hline
\end{tabular}

Homorganic ejectives show the same pattern, so the crucial ranking would be CORR-K' $\leftrightarrow K>>$ either IDENT-OI $(\mathrm{cg})$ or IDENT-IO(cg). By positioning the input-output faithfulness constraint between the CORR-CC constraint that refers to homorganic $\left(\mathrm{K}^{\mathrm{h}} \leftrightarrow \mathrm{K}\right)$ and the one that encompasses heterorganic $\left(\mathrm{K}^{\mathrm{h} \leftrightarrow \mathrm{T}}\right.$ ), we model the restriction of laryngeal agreement to apply only between homorganic stops.

5.2.2 Double Glottalization. The difference between aspirated stops and ejectives is that heterorganic ejectives may not cooccur: $*\left[t^{\prime}\right.$ ank'a]. This follows from separate restrictions on the distribution of ejective stops in Bolivian Aymara. First, only one ejective is allowed per morpheme unless they are identical. Second, this single ejective must be positioned as far to the left edge as possible. We draw on the analysis presented in MacEachern (1999), which proposes the following constraints: 


\section{a. $\operatorname{LEFTMOST}(\mathrm{CG})$}

[cg] features should occur early in the morpheme. One violation is assessed for every available host consonant intervening between the beginning of the morpheme and the location of the $[\mathrm{cg}]$ feature.

b. *IDENTITY \& *2CG

No cooccurrence of two identical segments and/or two ejectives.

In the LEFTMOST constraint, a 'host' consonant is defined as one that may bear glottalization, in other words, a stop. The second constraint is a conjunctive constraint that incurs violations if either of the two conditions are encountered (following Hewitt \& Crowhurst 1996).

These constraints are inserted into the correspondence hierarchy established above between CORR-K' $\leftrightarrow \mathrm{K}$ and the IDENT constraints. This positioning is crucial to capture the difference between double glottalization of homorganic stops and single glottalization for heterorganic stops. We give two possible inputs, one with a single ejective and another with two ejectives. In each case, the hierarchy produces the same output. The conjunctive constraint and LEFTMOST eliminate candidates (67b) and (67c), respectively, and the other candidates are decided by faithfulness.

(67) LEFTMOST(cg), *IDENT\&*2cg >>IDENT-IO(cg)

\begin{tabular}{|c|c|c|c|c|c|c|c|c|}
\hline /t'ank'a/ & $\begin{array}{c}\text { ID-CC } \\
(\mathrm{cg})\end{array}$ & $\begin{array}{l}\text { CORR- } \\
\mathrm{K}^{\prime} \leftrightarrow \mathrm{K}^{\prime}\end{array}$ & $\begin{array}{l}\text { CORR- } \\
\mathrm{K}^{\prime} \leftrightarrow \mathrm{K}\end{array}$ & $\begin{array}{c}\text { LEFT } \\
(\mathrm{cg})\end{array}$ & $\begin{array}{l}* \text { ID \& } \\
* 2 \mathrm{cg}\end{array}$ & $\begin{array}{c}\text { ID-IO } \\
(\mathrm{cg})\end{array}$ & $\begin{array}{c}\text { ID-OI } \\
(\mathrm{cg})\end{array}$ & $\begin{array}{l}\text { CORR- } \\
\mathrm{K}^{\prime} \leftrightarrow \mathrm{T}\end{array}$ \\
\hline a. 昵 $^{\prime} \mathrm{t}_{\mathrm{x}} \mathrm{ank}_{\mathrm{y}} \mathrm{a}$ & & & & & & * & & * \\
\hline b. $\quad \mathrm{t}_{\mathrm{x}}{ }^{\mathrm{ank}} \mathrm{k}_{\mathrm{x}}{ }^{\mathrm{a}}$ & & & & & $* !$ & & & \\
\hline c. $\quad t_{x}$ ank ${ }_{y}^{\prime} a$ & & & & $* !$ & & * & & $*$ \\
\hline d. $\quad t_{x} a k_{y} a$ & & & & & & $* * !$ & & $*$ \\
\hline e. $\quad \mathrm{t}_{\mathrm{x}} \mathrm{ank} \mathrm{k}_{\mathrm{x}} \mathrm{a}$ & $* !$ & & & $*$ & & $*$ & & \\
\hline f. $\quad \mathrm{t}^{\prime}{ }_{\mathrm{x}} \mathrm{ank}_{\mathrm{x}} \mathrm{a}$ & $* !$ & & & & & $*$ & & \\
\hline
\end{tabular}

(68)

\begin{tabular}{|c|c|c|c|c|c|c|c|c|}
\hline /t'anka/ & \begin{tabular}{|c} 
ID-CC \\
$(\mathrm{cg})$
\end{tabular} & $\begin{array}{l}\text { CORR- } \\
\mathrm{K}^{\prime} \leftrightarrow \mathrm{K}^{\prime} \\
\end{array}$ & $\begin{array}{l}\text { CORR- } \\
\mathrm{K}^{\prime} \leftrightarrow \mathrm{K} \\
\end{array}$ & $\begin{array}{l}\text { LEFT } \\
(\mathrm{cg})\end{array}$ & $\begin{array}{l}* \text { *ID \& } \\
* 2 \mathrm{cg} \\
\end{array}$ & $\begin{array}{c}\text { ID-IO } \\
(\mathrm{cg})\end{array}$ & $\begin{array}{c}\text { ID-OI } \\
(\mathrm{cg})\end{array}$ & $\begin{array}{l}\text { Corr- } \\
\mathrm{K}^{\prime} \leftrightarrow \mathrm{T} \\
\end{array}$ \\
\hline a. $\mathrm{t}^{\prime} \mathrm{x}^{\mathrm{ank}} \mathrm{y}$ & & & & & & & & $*$ \\
\hline b. $\quad \mathrm{t}^{\prime}{ }_{\mathrm{x}}$ ank ${ }_{\mathrm{x}} \mathrm{a}$ & & & & & $* !$ & & $*$ & \\
\hline c. $t_{x} a^{2} k_{y}^{\prime}{ }^{a}$ & & & & $* !$ & & $*$ & $*$ & $*$ \\
\hline d. $\quad t_{x} a^{a n k} k_{y}$ & & & & & & $* !$ & & $*$ \\
\hline e. $\quad t_{x} a n k_{x}^{\prime}{ }^{a}$ & $* !$ & & & * & & $*$ & $*$ & \\
\hline f. $\quad t_{x}^{\prime} a^{a n k_{x}}$ a & $* !$ & & & & & & & \\
\hline
\end{tabular}

In contrast to the heterorganic stops, wedging the two new constraints below the correspondence constraint pertaining to homorganic stops forces [cg] to appear on both stops, as shown in (69). This time, candidate (69b) with a single glottalization is eliminated by a CORR-CC constraint. The tableau in (70) illustrates the ranking of IDENT-IO(cg) >> IDENT-OI(cg). Recall that the reverse is also possible, in which case candidate (70c) with no glottalization would be selected. 
(69)

\begin{tabular}{|c|c|c|c|c|c|c|c|c|}
\hline /t'ant'a/ & $\begin{array}{c}\text { ID-CC } \\
(\mathrm{cg}) \\
\end{array}$ & $\begin{array}{l}\text { CORR- } \\
\mathrm{K}^{\prime} \leftrightarrow \mathrm{K}^{\prime} \\
\end{array}$ & $\begin{array}{l}\text { CORR- } \\
\mathrm{K}^{\prime} \leftrightarrow \mathrm{K} \\
\end{array}$ & $\begin{array}{c}\text { LEFT } \\
(\mathrm{cg}) \\
\end{array}$ & $\begin{array}{c}* \text { ID \& } \\
* 2 \mathrm{cg} \\
\end{array}$ & $\begin{array}{c}\text { ID-IO } \\
(\mathrm{cg}) \\
\end{array}$ & $\begin{array}{c}\text { ID-OI } \\
(\mathrm{cg}) \\
\end{array}$ & $\begin{array}{l}\text { CORR- } \\
\mathrm{K}^{\prime} \leftrightarrow \mathrm{T} \\
\end{array}$ \\
\hline a. $\mathrm{t}^{\prime}{ }_{\mathrm{x}} \mathrm{ant}^{\prime}{ }_{\mathrm{x}} \mathrm{a}$ & & & & & $*$ & & & \\
\hline b. $\quad \mathrm{t}_{\mathrm{x}} \mathrm{ant}_{\mathrm{y}} \mathrm{a}$ & & & $* !$ & & & $*$ & & $*$ \\
\hline c. $\quad t_{x} a_{n} t_{x} a$ & & & & & $*$ & $* * !$ & & \\
\hline d. $\quad t_{x} a^{a n t^{\prime}}{ }_{x} a$ & $* !$ & & & $*$ & & $*$ & & \\
\hline e. $\quad t_{x}$ ant' ${ }_{y} a$ & & & $* !$ & $*$ & & * & & $*$ \\
\hline f. $\quad t^{\prime}{ }_{x} a_{x}{ }_{x}$ & $* !$ & & & & & $*$ & & \\
\hline
\end{tabular}

(70) IDENT-IO(cg) >> IDENT-OI(cg)

\begin{tabular}{|c|c|c|c|c|c|c|c|c|}
\hline /t'anta/ & $\begin{array}{c}\text { ID-CC } \\
\text { (cg) }\end{array}$ & $\begin{array}{l}\text { CORR- } \\
\mathrm{K}^{\prime} \leftrightarrow \mathrm{K}^{\prime}\end{array}$ & $\begin{array}{l}\text { CORR- } \\
\mathrm{K}^{\prime} \leftrightarrow \mathrm{K}\end{array}$ & $\begin{array}{l}\text { LEFT } \\
(\mathrm{cg})\end{array}$ & $\begin{array}{l}* \text { ID \& } \\
* 2 \mathrm{cg}\end{array}$ & $\begin{array}{c}\text { ID-IO } \\
(\mathrm{cg})\end{array}$ & $\begin{array}{c}\text { ID-OI } \\
(\mathrm{cg})\end{array}$ & $\begin{array}{l}\text { CORR- } \\
\mathrm{K}^{\prime} \leftrightarrow \mathrm{T} \\
\end{array}$ \\
\hline a. $\mathrm{t}_{\mathrm{x}} \mathrm{ant}_{\mathrm{x}} \mathrm{a}$ & & & & & $*$ & & $*$ & \\
\hline b. $\quad \mathrm{t}_{\mathrm{x}} \mathrm{ant}_{\mathrm{y}}^{\mathrm{a}}$ & & & $* !$ & & & & & $*$ \\
\hline c. $t_{\mathrm{x}} \mathrm{ant}_{\mathrm{x}} \mathrm{a}$ & & & & & $*$ & $* !$ & & \\
\hline d. $\quad t_{x} a t^{\prime}{ }_{x} a$ & $* !$ & & & $*$ & & $*$ & & \\
\hline e. $\quad t_{x} a n t^{\prime}{ }_{x} a$ & & & $* !$ & $*$ & & $*$ & & $*$ \\
\hline f. $\quad t^{\prime}{ }_{x}$ ant $_{x} a$ & $* !$ & & & & & & & \\
\hline
\end{tabular}

Finally, let us consider an input in which the [cg] feature is not associated with the leftmost stop in the input. Any output candidate that preserves this pattern with homorganic stops will be eliminated by the high-ranking CORR-K' $\leftrightarrow \mathrm{K}$ constraint. In the case of heterorganic stops, such a candidate is eliminated due to LEFTMOST as in (71e) and it falls to the general faithfulness constraints to decide the winner.

(71)

\begin{tabular}{|c|c|c|c|c|c|c|c|c|}
\hline /tank'a/ & $\begin{array}{c}\text { ID-CC } \\
(\mathrm{cg})\end{array}$ & $\begin{array}{l}\text { CORR- } \\
\mathrm{K}^{\prime} \leftrightarrow \mathrm{K}^{\prime}\end{array}$ & $\begin{array}{l}\text { CORR- } \\
\mathrm{K}^{\prime} \leftrightarrow \mathrm{K} \\
\end{array}$ & $\begin{array}{l}\text { LEFT } \\
(\mathrm{cg})\end{array}$ & $\begin{array}{c}* \text { ID \& } \\
* 2 \mathrm{cg}\end{array}$ & $\begin{array}{c}\text { ID-IO } \\
(\mathrm{cg})\end{array}$ & $\begin{array}{c}\text { ID-OI } \\
(\mathrm{cg})\end{array}$ & $\begin{array}{l}\text { CORR- } \\
\mathrm{K}^{\prime} \leftrightarrow \mathrm{T} \\
\end{array}$ \\
\hline a. $\mathrm{t}_{\mathrm{x}} \mathrm{ank}_{\mathrm{y}} \mathrm{a}$ & & & & & & * & & $*$ \\
\hline b. $\quad t^{\prime}{ }^{a n k}{ }^{\prime} a$ & & & & & $* !$ & & * & \\
\hline c. $\quad \mathrm{t}_{\mathrm{x}} \mathrm{ank}_{\mathrm{y}} \mathrm{a}$ & & & & & & $*$ & $* !$ & * \\
\hline d. $\quad \mathrm{t}_{\mathrm{x}}$ ank $\mathrm{x}_{\mathrm{x}} \mathrm{a}$ & $* !$ & & & $*$ & & & & \\
\hline e. $\quad t_{x}$ ank' ${ }_{y}^{a}$ & & & & $* !$ & & & & * \\
\hline
\end{tabular}

Not all [cg] specifications align with the left edge in Bolivian Aymara. There are words with an initial sonorant or fricative consonant that does not license [cg], captured with a constraint *CONT/CG. In this case, the single ejective may appear elsewhere in the root. It is not deglottalized due to IDENT-IO $(\mathrm{cg})$. The winning candidate incurs no violations of LEFTMOST as the ejective $i s$ the leftmost stop in the root. 
(72)

\begin{tabular}{|l||c|c|c|c|c|}
\hline$/$ /sirk'u/ & $\begin{array}{c}\text { CONT/ } \\
\text { CG }\end{array}$ & $\begin{array}{c}\text { LEFT } \\
(\mathrm{cg})\end{array}$ & $\begin{array}{c}* \text { ID \& } \\
* 2 \mathrm{cg}\end{array}$ & $\begin{array}{c}\text { ID-IO } \\
(\mathrm{cg})\end{array}$ & $\begin{array}{c}\text { ID-OI } \\
(\mathrm{cg})\end{array}$ \\
\hline \hline a. s'irk'u & $* !$ & & & & $*$ \\
\hline b. ${ }^{2}$ sirk'u & & & & & \\
\hline c. sirku & & & & $* !$ & \\
\hline
\end{tabular}

Our analysis can also accommodate roots in which there are two non-initial stops. Only the leftmost one will be glottalized if they are heterorganic. According to Davidson (1977), Aymara roots are of the structure $\mathrm{CVCV}(\mathrm{CV}), \mathrm{CVCCV}$ or $\mathrm{VC}(\mathrm{C}) \mathrm{V}$. The first consonant in a cluster is either a sonorant or a fricative. Thus, there are only rare cases in which two stops occur in a root whereby neither is in initial position. MacEachern cites the form [hat'eqa] 'scratch', although it is not clear that this is monomorphemic. Nevetheless, we predict that this form is possible given our rankings, as shown in (73).

(73)

\begin{tabular}{|c|c|c|c|c|c|c|c|c|}
\hline /hat'eq'a/ & $\begin{array}{c}\text { ID-CC } \\
\text { (cg) }\end{array}$ & $\begin{array}{l}\text { CORR- } \\
\mathrm{K}^{\prime} \leftrightarrow \mathrm{K}^{\prime}\end{array}$ & $\begin{array}{l}\text { CORR- } \\
\mathrm{K}^{\prime} \leftrightarrow \mathrm{K}\end{array}$ & $\begin{array}{l}\text { LEFT } \\
(\mathrm{cg})\end{array}$ & $\begin{array}{l}* \text { ID \& } \\
* 2 \mathrm{cg}\end{array}$ & $\begin{array}{c}\text { ID-IO } \\
\text { (cg) }\end{array}$ & $\begin{array}{l}\text { ID-OI } \\
\text { (cg) }\end{array}$ & $\begin{array}{l}\text { CORR- } \\
\mathrm{K}^{\prime} \leftrightarrow \mathrm{T}\end{array}$ \\
\hline a. hat' $_{\mathrm{x}} \mathrm{eq}_{\mathrm{x}}{ }^{\mathrm{a}}$ & & & & & $* !$ & & & \\
\hline b. hat' $_{\mathrm{x}} \mathrm{eq}_{\mathrm{y}} \mathrm{a}$ & & & & & & $*$ & & $*$ \\
\hline c. hat $_{\mathrm{x}} \mathrm{eq}_{\mathrm{y}}^{\prime \mathrm{a}}$ & & & & $* !$ & & $*$ & & $*$ \\
\hline d. $\quad$ hat $_{\mathrm{x}} \mathrm{eq}_{\mathrm{y}} \mathrm{a}$ & & & & & & $* * !$ & & * \\
\hline
\end{tabular}

There are some additional complications in Aymara which we do not delve into here. Ejectives and aspirated stops obey ordering restrictions, with ejectives preceding aspirated stops. The order is reversed, however, if the initial consonant is labial or uvular. MacEachern (1999) argues that this is due to markedness restrictions against labial and uvular ejectives, ranked over those pertaining to other ejectives, which are more common cross-linguistically.

In conclusion, Bolivian Aymara resembles Chaha in imposing an MSC on roots such that stops must agree for laryngeal features, either [sg] or [cg]. It differs from Chaha in that heterorganic stops do not respect this condition. This is captured by ranking faithfulness constraints in different positions with respect to the CORR-K' $\leftrightarrow \mathrm{T}$ constraint in the hierarchy, illustrated in (74) for the feature $[\mathrm{cg}]$, which is common to both languages.

$$
\begin{array}{ll}
\text { Chaha: } & \text { CORR-K' } \leftrightarrow \mathrm{K} \gg \text { C CORR-K' } \leftrightarrow \mathrm{T}>\text { IDENT-IO(cg), IDENT-OI(cg) } \\
\text { Bolivian Aymara: } & \text { CORR-K' } \leftrightarrow \mathrm{K}>>\text { IDENT-IO(cg), IDENT-OI(cg) }>\text { CORR-K' } \leftrightarrow \text { T }
\end{array}
$$

The same arguments raised for Chaha with respect to spreading or double-linking of the features [cg] and [sg] between stops also apply to Bolivian Aymara. This language has no proximity restriction, and agreement may apply across other segments, including fricatives ([k'ask'a] 'acid to the taste') and sonorants ([t'ant'a] 'bread'). There is no indication that these segments are also glottalized. Under an LDAC analysis, intervening segments are ignored, as they are dissimilar from oral stops and do not enter into correspondence relations.

\section{DIAGNOSTICS OF AGREEMENT AND IMPLICATIONS FOR CORONAL HARMONY}

We are now in a position to sum up the characteristics of LDAC in comparison to feature-linkage phenomena. Our claim is that both LDAC and feature-linkage phenomena exist, but they behave in 
distinct ways and should be analyzed differently. We establish several diagnostics of LDAC and then consider the implications of our diagnostics for the analysis of coronal harmony.

6.1 DIAGNOSTICS OF AGREEMENT. In comparing LDAC with feature linkage or spreading, we will be assessing harmonies that have been analyzed using either local spreading over a continuous span or long-distance spreading with a gapped configuration. The major points of divergence are the blocking effects and the determination of participants in harmony.

Diagnostic 1: Blocking by incompatible segments

In LDAC phenomena, intervening segments are unaffected by the agreeing feature, but in local spreading, segments incompatible with the spreading feature may block spreading. For example, [nasal] agreement may operate over obstruents, but in true nasal harmony (i.e. spreading) obstruents frequently block spread of [nasal], as in Ijo (Walker 1998[2000]). Another example of a similar effect is emphasis harmony of some dialects of Arabic, which may be halted by high vowels and palatal consonants (Davis 1995).

Diagnostic 2: Blocking by specified segments

In LDAC, intervening segments that are specified for the agreeing feature do not block. For example, voiced segments in [voice] agreement do not block. Spreading, however, can be blocked by segments that bear the spreading feature. One example is the behavior of retroflex stops in Sanskrit retroflex harmony, which block retroflexion from being spread to nasal consonants to their right. Gafos (1996[1999]) treats Sanskrit retroflexion as local spreading that affects all segments in a span, including vowels.

Diagnostic 3: Interacting segments

The segments that interact in LDAC phenomena is determined by similarity. For example, the class of stops out of the larger class of obstruents are singled out for [voice] agreement. We have also identified cases of LDAC that operate among homorganic segments only. Likewise, in the case of long-distance nasal agreement, the set of participants is limited to nasals and segments that are similar to them, namely voiced stops and approximant consonants. The interacting segments in spreading harmonies are often determined as a by-product of spreading. In nasal harmony or emphasis harmony, the target of spreading is not specified, but the feature is aligned with the edge of some domain. Alignment of the feature can compel participation of all segments within the domain. On the other hand, if specific targets are singled out in harmonies, one proposal (Gafos 1996[1999]) maintains that it is the contrastive nature of the segments that determines their participation as targets or triggers of harmony.

In sum, local spreading harmonies affect a string of segments and may exhibit blocking effects. Participating segments are determined by their location in the spreading domain or by contrast within the system. LDAC phenomena show no blocking, operate at a distance and participants are determined by similarity. These characteristics lead to an interesting dilemma with respect to coronal harmonies, which we investigate in the next section.

6.2 CORONAL HARMONY. Coronal harmony refers to patterns of agreement for features only relevant to coronals. Coronal harmony is compatible with the characteristics of LDAC along two dimensions: there is no blocking and interacting segments are highly similar (as discussed in $\S 3.1 .1 .4)$. On the other hand, coronal harmony is also compatible with the characteristics of spreading if the spreading feature is tongue-tip constriction area or orientation as argued in Gafos (1996[1999]). As we note below, Sanskrit appears to present some divergent properties that set it apart from the majority of cases. 
6.2.1 SPREADING ANALYSES. Earlier analyses of coronal harmony characterize it using the features [anterior] and/or [distributed] or [strident] (Poser 1982, Steriade 1987, Shaw 1991, among others). Harmony is expressed as either spreading of these individual features (see Chumash in (3)) or spreading of the Coronal node that dominates them. Shaw (1991) proposes the latter representation for Tahltan coronal harmony. Transparent intervening vowels and consonants lack a Coronal node. Vowels are assumed to be specified with a Dorsal node, and non-coronal consonants are not specified on the Coronal tier. Coronal segments such as [ $\left[\begin{array}{lll}\mathrm{n} & 1 \mathrm{f}\end{array}\right]$ and the lateral affricates are unspecified for Coronal:

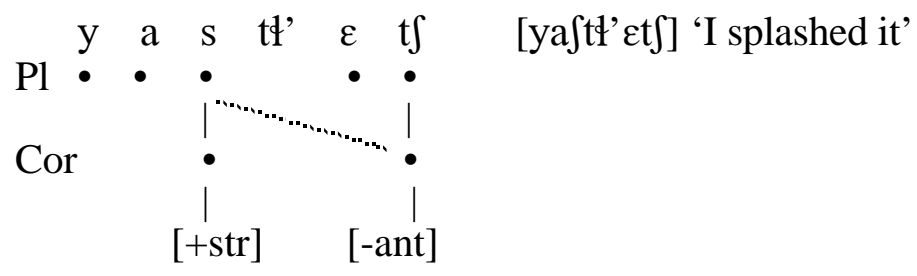

Problematic for these analyses is the radical underspecification of other anterior sounds, such as stops and laterals (see Kaun 1993). In addition, we have already mentioned the problem of gapped configurations. Finally, as Gafos (1996) points out, if the Coronal node can spread, it is not clear why other place nodes such as Labial cannot spread if intervening sounds are not specified for Labial.

Gafos (1996[1999]) argues that sibilant harmonies are best analyzed involving the feature [TTCA], a scalar feature which specifies the shape of the tip-blade on the cross-sectional dimension, a feature only relevant for coronal fricatives and affricates. The sounds $\left[\theta \int \mathrm{s}\right]$ are wide, mid and narrow [TTCA] respectively. Another feature [TTCO] contrasts apical and laminal articulations and is used to characterize retroflex consonants. It is claimed that the spread feature affects all segments in the harmonic span; yet the phonetic effect of [TTCA] or [TTCO] on other segments is imperceptible or is so slight as to be unreported by researchers (see also Flemming 1995b, Ní Chiosáin \& Padgett to appear for similar ideas). Manipulation of the tip-blade has no significant effect on the acoustic quality of intervening vowels or non-coronal consonants, which are produced with the tongue dorsum or with separate articulators. As for coronal stops, Gafos hypothesizes that they may be pronounced as either apical or laminal in TTCO harmony, depending on the harmony span in which they are found. In the case of [TTCA], the tongue blade may still be shaped as flat or grooved behind the tongue tip closure of stops.

In comparing a spreading analysis to an LDAC analysis of coronal harmonies, we will focus on the diagnosis of interacting segments. In an LDAC analysis, interacting segments are determined by similarity. Under the local spreading theory in Gafos (1996[1999]), segments perceived as participating in the harmony are those that contrast for the spreading feature. Dental agreement in two Nilotic languages bears on this issue and points favorably towards an agreement analysis.

6.2.2 NiLOTIC DENTAL AGREEMENT. As discussed in $\S 3$, alveolar/(inter)dental contrasts are prevalent in Western Nilotic languages, such as Mayak (Andersen 1999), Anywa or Anuak (Reh 1996), Paeri (Andersen 1988), DhoLuo (Tucker 1994) and Shilluk (Gilley 1992). In most of these languages, agreement is only found as an MSC holding over the cooccurrence of oral alveolar/dental stops [ $\mathrm{t}_{n} \mathrm{t} \mathrm{d}$ ] in a root. In those languages that have a contrast between [n] and [n], such as Shilluk and Paeri, the nasal stop also participates in the agreement. DhoLuo and Anywa form an interesting pair in that both lack a phonemic /n/, but in Anywa, [n] surfaces in agreement. 
In Anywa (Reh 1996), there is no cooccurrence of dental and alveolar stops in a root. This also pertains to the nasals, even though $[\mathrm{n}]$ is almost entirely derivable from $/ \mathrm{n} /$. Reh (1996:24) states that 'there is no single word in the language with a simple dental nasal which does not comprise a dental stop as well'. Examples of stems are given in (76). ${ }^{32}$ Word-final voiced stops are devoiced, which is not indicated here:

$\begin{array}{llll}\text { Dental } & & \text { Alveolar } & \\ \text { nùdò } & \text { 'to lick (sugar)' } & \text { núudó } & \text { 'to press something down' } \\ \text { ỡoòn } & \text { 'mud' } & \text { dīn } & \text { 'to thresh something' } \\ \text { tirnn } & \text { 'to be small' } & \text { tòn } & \text { 'to leak (a bit)' } \\ \text { tùn } & \text { 'ropes' } & \text { tūud } & \text { 'pus' }\end{array}$

The dental nasal arises through agreement, and it may also emerge as a nasal mutation alternant of oral dental stops, e.g. /póod̄/ 'be smooth' -> [pòonnò] 'become smooth'.

DhoLuo has the same inventory of dental and alveolar stops as Anywa: / $\mathrm{d} t \mathrm{t} \mathrm{n} /$. The root structure constraints pertain to the oral stops. Unlike in Anywa, no dental nasal arises through agreement, and the nasal alveolar may cooccur with dental stops, as shown in (77).

$\begin{array}{ll}\text { Dental } & \text { Alveolar } \\ \text { teedo 'to forge' } & \text { teeds 'to cook' } \\ \text { dodo 'to suckle' } & \text { dieeds 'to balance' } \\ \text { cf. tuuns 'breast' } & \\ \text { tuosn 'brave man' } & \end{array}$

A nasal may be pronounced as dental when part of a prenasalized stop, suggesting that a dental nasal is not an impossible sound in the language, but it is simply restricted to a local, coarticulation environment.

Returning to our main point, the agreement patterns of Anywa and DhoLuo are counterexamples to the position taken in Gafos (1996[1999]), namely that the contrastive nature of the inventory determines which segments will participate in harmony. Under the LDAC analysis, the patterns follow the similarity hierarchy. In Anywa, all dental and alveolar stops participate in agreement. In DhoLuo, only the oral dental and alveolar stops do. Faithfulness constraints positioned in the appropriate place in the similarity hierarchy capture the difference between the two languages. These examples of coronal harmony are successfully analyzed as cases of LDAC, and we can conceive of a similar analysis applied to the sibilant and retroflex examples outlined in $\S 3.1 .1 .4$. Nevertheless, cases of coronal harmony such as Sanskrit, which shows blocking effects and participation of non-similar segments (i.e. a nasal target and continuant triggers), might be better analyzed as local spreading under the analysis advocated by Gafos. However, without instrumental analysis of the intervening segments, it is not possible to definitively decide between the two approaches.

\section{FURTHER ISSUES AND CONCLUSION}

As discussed in $\S 3.1$, there are two groups of features that consistently do not display longdistance agreement. The first group consists of the stricture features [sonorant], [consonantal], and [continuant]. Although these features are recognized as having a classification function, they do not

32 There is one word in which the nasal does not agree for dentality: [dàanó] 'person', which Reh assumes was historically a compound. 
appear to be active in the same sense as other features. In particular, these features fail to enter into either local assimilations or long-distance agreement.

The second group of features that fail to show agreement at a distance is the major C-Place features. Although local spreading of Place features is attested, we know of no cases of longdistance major place agreement between two consonants over intervening vowels. The absence of this type of interaction has been a puzzle in recent phonological theory. Ní Chiosáin \& Padgett (1997) and Padgett (1995b) speculate that if spreading is local, spreading of major place features across a vowel also entails spreading of stricture features, which are incompatible with intervening vowels. This is explicitly represented in the articulator group model of feature geometry advocated in Padgett (1995b). Yet there is another compelling observation about the nature of place assimilations. They typically involve coda-onset sequences in which the coda assimilates to the onset. This is expressed through markedness conditions on codas (Steriade 1982, Itô 1986[1988]) or as faithfulness to onsets (Beckman 1998, Lombardi 1999). Jun (1996) claims that casual speech place assimilations involve gestural reduction (but not elimination) of the coda segment, giving the perception of assimilation.

To bring this back to long distance agreement, long-distance interactions involve consonants that are in different, unconnected prosodic positions. There is no coarticulation impetus for place gestures to be reduced, and accordingly, it appears that retention of place features is high. This is supported by a recent kinematic study of speech errors by Pouplier et al. (1999), which investigated interaction of non-local stops of different place of articulation. They found that errors involving place gestures in initial stops in the phrase 'cop top' actually involved the intrusive production of a dorsal place in addition to the original coronal place gesture. But these stops were actually perceived as $[\mathrm{k}]$. Our interpretation is that place feature errors can produce the perception of one feature replacing another, although the segments are actually produced as complex stops. We propose that the additive property of speech errors with place is mirrored in consonantal agreement in the respect that place articulations can be added but not removed. Place agreement is avoided, because complex stops are generally dispreferred. Place features stand apart from the others, such as [nasal] and the laryngeal features, because place specifications involve separate articulators.

Our goal in this paper is to argue that certain cases of long-distance 'harmonies' should be analyzed as featural agreement mediated through an output-based correspondence relation rather than as spreading or multiple linking of features. The correspondence analysis enjoys several advantages over spreading-based accounts. First, it accounts for the behavior of intervening segments either specified or unspecified for the agreeing feature. In long-distance agreement, intervening segments that do not participate in the agreement are transparent to it. Second, agreement is based on similarity of the interacting segments, which must share a core stricture value of [cont] or [son]. Output-based correspondence constraints form the core of our analysis, with constraints arrayed according to a scale of descending similarity. This allows us to account straightforwardly for variation between languages with respect to the typology of interacting segments in agreement. Faithfulness constraints are positioned at different locations in the hierarchy, delimiting the extent to which segments interact through agreement.

LDAC patterns fall into four main groups: nasal, laryngeal, liquid and coronal. We provided detailed analyses of the agreement patterns of four languages. Kikongo and Ngbaka showed nasal agreement at a distance and differed by the imposition of additional homorganicity requirements. Similarly, Bolivian Aymara and Chaha showed laryngeal agreement for voicing as well as one other state of the glottis articulation. Again, they differed by whether agreement was restricted to homorganic segments. Finally, coronal 'harmony' proved ambiguous with respect to spreading versus agreement. We outlined how at least one case of dental harmony could be analyzed fruitfully using the agreement model. 
A model of output-based agreement has already been successfully applied to vowel harmony (Baković 2000, Krämer to appear), and further extensions can be imagined with respect to transparent vowels. Similarity also plays a role in distance dissimilation and future research may illuminate how dissimilation differs from long-distance agreement. One striking divergence is the propensity for place dissimilations and OCP effects on place, which are notably absent from agreement. 


\section{References}

Andersen, Torben. 1988. Consonant alternation in the verbal morphology of Päri. Afrika und Übersee 71, 63-113.

-1999. Consonant alternation and verbal morphology in Mayak (Northern Burun). Afrika und Übersee 82, 65-97.

Ao, Benjamin. 1991. Kikongo nasal harmony and context-sensitive underspecification. LI 22, 193-96.

Archangeli, Diana \& Douglas Pulleyblank. 1987. Maximal and minimal rules: The effects of tier scansion. NELS 17, 16-35.

. 1994. Grounded Phonology. Cambridge, MA: The MIT Press.

Baković, Eric. 2000. Harmony, Dominance and Control. PhD dissertation, Rutgers University.

Banksira, Degif Petros. 2000. Sound Mutations: The Morphophonology of Chaha. Amsterdam: John Benjamins.

Bat-El, Outi. 1988. Remarks on tier conflation. LI 19, 477-85.

Beckman, Jill. 1998. Positional faithfulness. PhD Dissertation, University of Massachusetts, Amherst.

Bentley, William H. 1887. Dictionary and Grammar of the Kongo Language. London: Baptist Missionary Society.

Bessell, Nicola. 1992. Towards a Phonetic and Phonological Typology of Post Velar Articulations. $\mathrm{PhD}$ dissertation, University of British Columbia.

- 1998. Local and non-local consonant-vowel interaction in Interior Salish. Phonology 15, 1-40.

Breeze, Mary. 1990. A sketch of the phonology and grammar of Gimira (Benchnon). In Richard Hayward, ed., Omotic Language Studies, pp. 1-67. London: SOAS.

Broe, Michael. 1993. Specification Theory: The Treatment of Redundancy in Generative Phonology. PhD dissertation, University of Edinburgh.

Buckley, Eugene, 1997. Tigrinya root consonants and the OCP. Penn Working Papers in Linguistics 4.3, 19-51.

Burzio, Luigi. 1999. Surface-to-Surface Morphology: When your representations turn into constraints. Ms. of paper presented at the 1999 Maryland Mayfest, University of Maryland, College Park.

- 2000. Segmental contrast meets output-to-output faithfulness. Ms., Johns Hopkins University.

Chamora, Berhanu. 1997. The Phonology of Inor Verbs. M.A. thesis, Université du Québec à Montréal.

Clements, G. N. 1986. Compensatory lengthening and consonant gemination in Luganda. In Leo Wetzels \& Engin Sezer, eds., Studies in Compensatory Lengthening, pp. 37-77 Foris: Dordrecht.

Clements, G. N. \& Elizabeth V. Hume. 1995. The internal organization of speech sounds. In John Goldsmith, ed., The Handbook of Phonological Theory, pp. 245-306. Oxford: Blackwell.

Cole, Jennifer. 1987. Planar Phonology and Morphology. PhD dissertation, MIT.

Davidson, Joseph. 1977. A contrastive study of the grammatical structures of Aymara and Cuzco Kechua. PhD dissertation, UC Berkeley.

Davis, Stuart. 1995. Emphasis spread in Arabic and grounded phonology. LI 26, 465-98.

De Lucca, Manuel. 1987. Diccionario aymara-castellano castellano-aymara. La Paz, Cochabamba: Editorial Los Amigos del Libro.

Dell, Gary S. 1984. Representation of serial order in speech: Evidence from the repeated phoneme effect in speech errors. Journal of Experimental Psychology: Learning, Memory, and Cognition 10, 222-33.

- 1986. A spreading activation theory of retrieval in sentence production. Psychological Review 93, 283-321.

Dell, Gary S. \& Peter Reich. 1980. Toward a unified model of slips of the tongue. In Victoria A. Fromkin, ed., Errors in Linguistic Performance, pp. 273-86. San Diego: Academic Press.

Dereau, Léon. 1955. Cours de Kikongo. Namur: A. Wesmael-Charlier. 
Doke, C. 1938. Textbook of Lamba Grammar. Johannesburg: Witwatersrand University Press.

Dolbey, Andrew \& Gunnar Hansson. 1999a. Phonetic naturalness is not encoded in synchronic phonology. Paper presented at HILP 4, Leiden University, January 28-30, 1999.

. 1999b. The Source of Naturalness in Synchronic Phonology. CLS 35.

Ebert, Karen. 1979. Sprache und Tradition der Kera (Tschad), Teil III: Grammatik. (Marburger Studien zur Afrika- und Asienkunde, Serie A: Afrika.) Berlin: Reimer.

Evans, Nick. 1995. Current issues in the phonology of Australian languages. In John Goldsmith, ed., The handbook of phonological theory, pp. 723 -61. Oxford: Blackwell.

Eynde, Karel van den. 1968. Elements de grammaire yaka. Kinshasa: Université Lovanium.

Fallon, Paul. 1998. The Synchronic and Diachronic Phonology of Ejectives. PhD dissertation, The Ohio State University.

Feinstein, M. H. 1979. Prenasalization and syllable structure. LI 10, 245-78.

Flemming, E. 1995a. Auditory Representations in Phonology. PhD dissertation, UCLA.

. 1995b. Vowels undergo consonant harmony. Paper presented at the Trilateral Phonology Weekend 5, University of California, Berkeley.

Frisch, Stefan. 1996. Similarity and Frequency in Phonology. PhD dissertation, Northwestern University.

Frisch, Stefan, Michael Broe \& Janet Pierrehumbert. 1997. Similarity and phonotactics in Arabic. Ms. Indiana University \& Northwestern University.

Frisch, Stefan \& Richard Wright. 1996-1997. A preliminary acoustic study of errors in speech production. Research on Spoken Language Processing Progress Report No. 21, Indiana University Speech Research Lab.

Fromkin, Victoria A. 1971. The non-anomalous nature of anomalous utterances. $\operatorname{Lg} 41,27-52$.

Gafos, Diamandis. 1996. The Articulatory Basis of Locality in Phonology. PhD dissertation, Johns Hopkins University. [Published by Garland, New York, 1999].

- 1998. Eliminating long-distance consonantal spreading. NLLT 16, 223-78.

Gafos, Diamandis \& Linda Lombardi. 1999. Consonant transparency and vowel echo. To appear in NELS 29

Gilley, Leoma. 1992. An Autosegmental Approach to Shilluk Phonology. Dallas, TX: The Summer Institute of Linguistics and the University of Texas at Arlington.

Gnanadesikan, Amalia. 1997. Phonology with Ternary Scales. PhD dissertation, University of Massachusetts, Amherst.

Goad, Heather. 1996. Codas, word minimality, and empty-headed syllables. In E. Clark, ed., Proceedings of the $28^{\text {th }}$ Annual Child Language Research Forum, pp. 113-22. Stanford: Center for the Study of Language and Information.

Goldsmith, John. 1976. Autosegmental Phonology. PhD dissertation, MIT.

Greenberg, Joseph. 1950. The patterning of root morphemes in Semitic. Word 6, 162-81.

Hamilton, Phillip. 1993. On the internal structure of the Coronal node. Proceedings of ESCOL 10, 129-140.

Hardman, M.J., J. Vasquez \& J. de D. Yapita Moya (eds.) 1974. The Aymara Language Project, volume III: outline of Aymara phonological and grammatical structure. Gainesville: Department of Anthropology, University of Florida.

Hayes, Bruce \& Tanya Stivers. 1995. A phonetic account of postnasal voicing. Ms., UCLA.

Hayward, Richard. 1990. Notes on the Aari language. In Richard Hayward, ed., Omotic Language Studies, 425-93. London: SOAS.

Herbert, Robert K. 1986. Language Universals, Markedness Theory, and Natural Phonetic Processes. New York: Mouton de Gruyter.

Hewitt, Mark \& Megan Crowhurst. 1996. Conjunctive constraints and templates in Optimality Theory. NELS 26, 101-16.

Hume, Elizabeth \& David Odden. 1996. Reconsidering [consonantal]. Phonology 13, 345-76.

Hyman, Larry. 1995. Nasal consonant harmony at a distance: The case of Yaka. Studies in African Linguistics 24, 5-30.

Itô, Junko. 1986. Syllable Theory in Prosodic Phonology. PhD dissertation, University of Massachusetts, Amherst. [Published by Garland, New York, 1988.] 
Itô, Junko \& Armin Mester. 1995. The core-periphery structure of the lexicon and constraints on reranking. In Jill Beckman, Laura Walsh Dickey, \& Suzanne Urbanczyk, eds., University of Massachusetts Occasional Papers: Papers in Optimality Theory 18, 181-209.

- 2000. Covert generalizations in Optimality Theory. Paper presented at NELS 31, Georgetown University.

Iverson, Gregory K. \& Joseph C. Salmons. 1996. Mixtec prenasalization as hypervoicing. IJAL $62,165-75$.

Jun, Jongho. 1996. Place assimilation is not the result of gestural overlap: Evidence from Korean and English. Phonology 13, 377-407.

Kaun, Abigail. 1993. The Coronal underspecification hypothesis. UCLA Occasional Papers in Linguistics 13, $69-108$.

Kidima, Lukowa. 1991. Tone and Accent in KiYaka. PhD Dissertation, UCLA.

Kimenyi, Alexandre. 1979. Studies in Kinyarwanda and Bantu Phonology. Edmonton, Alberta: Linguistics Research Inc.

Kirchner, Robert. 1998. An Effort-Based Approach to Consonant Lenition. PhD dissertation, UCLA.

Kitto, Catherine \& Paul de Lacy. 1999. Correspondence and epenthetic quality. Proceedings of The Sixth Meeting of the Austronesian Formal Linguistics Association, pp. 181-200. TWPL, Toronto: University of Toronto.

Krämer, Martin. To appear. Yucatec Maya vowel alternations - Harmony as Syntagmatic Identity. Zeitschrift für Sprachwissenschaft 20.2.

Kupin, Joseph. 1982. Tongue Twisters as a Source of Information about Speech Production. Bloomington: IULC.

Laman, Karl E. 1936. Dictionnaire Kikongo-Français. [Republished in 1964.] Ridgewood,New Jersey: Gregg Press.

Leslau, Wolf. 1967. The impersonal in Chaha. To Honor Roman Jakobson. Essays on the Occasion of his Seventieth Birthday, pp. 1150-62. The Hague: Mouton.

- 1979. Etymological Dictionary of Gurage (Ethiopic). Wiesbaden: Otto Harrassowitz.

Lombardi, Linda. 1991. Laryngeal features and laryngeal neutralization. PhD dissertation, University of Massachusetts, Amherst. [Published by Garland, New York 1994].

- 1999. Positional faithfulness and voicing assimilation in Optimality Theory. NLLT 17, 267-302.

Lowenstamm, Jean. 1996. Five puzzling Chaha verbs. In Grover Hudson, ed., Essays on Gurage Language and Culture, pp. 123-32. Wiesbaden: Harrassowitz.

MacEachern, Margaret. 1996. Ordering restrictions in aspirated and ejective stops in Aymara. $B L S$ 22, 244-54.

. 1997. Laryngeal Cooccurrence Restrictions. PhD dissertation, UCLA. [Published by Garland, New York, 1999]

MacKay, Donald G. 1970. Spoonerisms: The structure of errors in the serial order of speech. Neuropsychologia 8, 323-50.

- 1987. The Organization of Perception and Action: A Theory for Language and Other Cognitive Skills. New York: Springer.

McCarthy, John. 1986. OCP effects: Gemination and antigemination. LI 17, 207-63. . 1988. Feature geometry and dependency: A review. Phonetica 43, 84-108.

1994. On coronal 'transparency'. Paper presented at the Trilateral Phonology Weekend 2, University of California, Santa Cruz.

McCarthy, John \& Alan Prince. 1993. Prosodic Morphology I: Constraint Interaction and Satisfaction. University of Massachusetts, Amherst \& Rutgers University.

—. 1994. Emergence of the unmarked: Optimality in Prosodic Morphology. In Mercè Gonzàlez, ed., NELS 24, pp. 333-79.

. 1995. Faithfulness and reduplicative identity. In Jill Beckman, Laura Walsh Dickey, \& Suzanne Urbanczyk, eds., University of Massachusetts Occasional Papers: Papers in Optimality Theory 18, 249-384. 
1999. Faithfulness and identity in prosodic morphology. In René Kager, Harry van der Hulst, \& Wim Zonneveld, eds., The Prosody-Morphology Interface, pp. 218-309. Cambridge, Cambridge University Press.

McGregor, William. 1990. A Functional Grammar of Gooniyandi. Amsterdam: John Benjamins.

Meinhof, Carl. 1932. Introduction to the Phonology of the Bantu Languages (trans. by N. J. van Warmelo). Berlin: Dietrich Reimer/Ernst Vohsen.

Mester, R. Armin. 1986. Studies in Tier Structure. PhD dissertation, University of Massachusetts, Amherst.

Mowrey, Richard A. \& Ian R. A. MacKay. 1990. Phonological primitives: Electromyographic speech error evidence. JASA 88, 1299-312.

Ní Chiosáin, Máire. 1991. Topics in the Phonology of Irish. PhD dissertation, University of Massachusetts, Amherst.

Ní Chiosáin, Máire \& Jaye Padgett. 1997. Markedness, segment realization, and locality in spreading. Report no. LRC-97-01, Linguistics Research Center, University of California, Santa Cruz.

- To appear. Markedness, segment realization, and locality in spreading. In Linda Lombardi, ed., Segmental Phonology in Optimality Theory. Cambridge University Press.

Nooteboom, S. G. 1967. Some regularities in phonemic speech errors. IPO Annual Progress Report II, 65-70.

Odden, David. 1994. Adjacency parameters in phonology. $\operatorname{Lg} 70,289-330$.

Padgett, Jaye. 1995a. Feature classes. In Jill Beckman, Laura Walsh Dickey, \& Suzanne Urbanczyk, eds., University of Massachusetts Occasional Papers: Papers in Optimality Theory $18,385-420$.

. 1995b. Stricture in Feature Geometry. CSLI publications, Stanford University.

Parker, Steve \& David Weber. 1996. Glottalized and aspirated stops in Cuzco Quechua. International Journal of American Linguistics 62, 70-85.

Pater, Joseph. 1999. Austronesian nasal substitution and other NC effects. In René Kager, Harry van der Hulst, \& Wim Zonneveld, eds., The Prosody-Morphology Interface, pp. 310-43. Cambridge, Cambridge University Press.

Petros (Banksira), Degif. 1993. La dérivation verbale en chaha. MA Thesis, Université du Québec à Montréal.

Pierrehumbert, Janet. 1993. Dissimilarity in the Arabic verbal roots. NELS 23, 367-81.

Piggott, G. L. 1992. Variability in feature dependency: The case of nasality. NLLT 10, 33-77.

- 1996. Implications of consonant nasalization for a theory of harmony. CJL 41, 141-74.

Poser, William. 1982. Phonological Representations and Action-at-a-Distance. In H. van der Hulst and N. Smith, eds., The Structure of Phonological Representations, Part II., pp. 121-58. Dordrecht: Foris Publications

Pouplier, Marianne, Larissa Chen, Louis Goldstein \& Dani Byrd. 1999. Kinematic evidence for the existence of gradient speech errors. Abstract. JASA 106.4 (Part 2), 2242.

Prince, Alan \& Paul Smolensky. 1993. Optimality Theory: Constraint Interaction in Generative Grammar. Ms. Rutgers University \& University of Colorado, Boulder. [To appear, MIT press.]

Prunet, Jean-François. 1991. A Note on Dialectal Variation in Ennemor. In Alan S. Kaye, ed., Semitic Studies in Honor of Wolf Leslau on the Occasion of his Eighty-fifth Birthday, vol. II, pp. 1220-25. Wiesbaden: Otto Harrassowitz.

1996a. Guttural Vowels. In Grover Hudson, ed., Essays on Gurage Language and Culture, pp. 175-203. Wiesbaden: Otto Harrassowitz.

- 1996b. Some core properties of Semitic morphology: Evidence from the far south. In J. Durand \& B. Laks, eds., Current Trends in Phonology, pp. 617-52. Salford: European Studies Research Institute, University of Salford Publications.

Reh, Mechthild. 1996. Anywa Language: Description and Internal Reconstructions. Köln: Rüdiger Köppe Verlag.

Reichard, G. 1938. Coeur d'Alene. In F. Boas, ed., Handbook of American Languages, Washington: Bureau of American Ethnology, Bulletin 40. 
Rice, Keren. 1993. A reexamination of the feature [sonorant]: The status of 'sonorant obstruents'. Lg 308-44.

Rose, Sharon. 1994. Palatalization, underspecification and plane conflation in Chaha. WCCFL 12, 101-16.

- 1997. Theoretical Issues in Comparative Ethio-Semitic Phonology and Morphology. PhD dissertation, McGill University.

. 2000. Rethinking geminates, long-distance geminates and the OCP. LI 31, 85-122.

Rosenthall, Samuel. 1994. Vowel/glide alternations in a theory of constraint interaction. $\mathrm{PhD}$ dissertation, University of Massachusetts, Amherst. [Published by Garland, New York, 1997].

Sagey, Elizabeth. 1986. The Representation of Features and Relations in Nonlinear Phonology. PhD dissertation, MIT.

Selkirk, Elisabeth O. 1984. On the major class features and syllable theory. In M. Aronoff \& R.T. Oehrle, eds., Language Sound Structure, pp. 107-36. Cambridge, MA: MIT Press.

Shattuck-Hufnagel, Stefanie. 1983. Sublexical units and suprasegmental structure in speech production planning. In Peter MacNeilage, ed., The Production of Speech, pp. 109-36. New York: Springer-Verlag.

- 1986. The representation of phonological information during speech production planning: Evidence from vowel errors in spontaneous speech. Phonology Yearbook 3, 117-49.

- 1987. The role of word-onset consonants in speech production planning: New evidence from speech error patterns. In Eric Keller \& Myrna Gopnik, eds., Motor and Sensory Processes of Language, pp. 17-51. Lawrence Erlbaum.

Shattuck-Hufnagel, Stefanie \& Dennis Klatt. 1979. The limited use of distinctive features and markedness in speech production. Journal of Verbal Learning and Verbal Behavior 18, 41-55.

Shaw, Patricia. 1991. Consonant harmony systems: The special status of coronal harmony. In Carole Paradis \& Jean-François Prunet, eds., The Special Status of Coronals: Internal and External Evidence, pp. 125-57. San Diego: Academic Press.

Smolensky, Paul. 1993. Harmony, markedness, and phonological activity. Paper presented at the Rutgers Optimality Workshop, Rutgers University.

- 1997. Constraint interaction in generative grammar II: Local conjunction. Paper presented at the Hopkins Optimality Theory Workshop/Maryland Mayfest 1997, Baltimore, MD.

Stafford, R. 1967. An elementary Luo grammar. Oxford: Oxford University Press.

Stemberger, Joseph P. 1982. The nature of segments in the lexicon: Evidence from speech errors. Lingua 56, 235-59.

- 1985. An interactive activation model of language production. In Andrew W. Ellis, ed. Progress in the Psychology of Language, Vol. 1. London: Lawrence Erlbaum Associates.

Steriade, Donca. 1982. Greek Prosodies and the Nature of Syllabification. PhD dissertation, MIT.

- 1987. Locality conditions and feature geometry. NELS 17, 595-617.

. 1993. Closure, release, and nasal contours. In Marie K. Huffman \& Rena Krakow, eds., Nasals, Nasalization, and the Velum. Phonetics and Phonology, Volume 5, pp. 401-70. San Diego: Academic Press.

- 1995. Underspecification and markedness. In John Goldsmith, ed., The Handbook of Phonological Theory, pp. 114-74. Oxford: Blackwell.

Straight, H. 1976. The acquisition of Maya phonology: Variation in Yucatec child language. New York: Garland.

Suzuki, Keiichiro. 1998. A Typological Investigation of Dissimilation. $\mathrm{PhD}$ dissertation, University of Arizona.

- 1999. Identity avoidance vs. identity preference: The case of Sundanese. Paper presented at the LSA, January 7, 1999, Los Angeles.

Thomas, Jacqueline. 1963. Le parler ngbaka de Bokanga. Paris: Mouton.

. 1970. Contes Ngbaka - Ma’bo. Paris: Éditions Klincksieck.

Trigo, Loren. 1993. The inherent structure of nasal segments. In Marie K. Huffman \& Rena Krakow, eds., Nasals, Nasalization, and the Velum. Phonetics and Phonology, Volume 5, pp. 369-400. San Diego: Academic Press. 
Tucker, Archibald. 1994. A Grammar of Kenya Luo (Dholuo). ed. by Chet Creider. Köln: Rüdiger Köppe Verlag.

Ussishkin, Adam. 1999. The inadequacy of the consonantal root: Modern Hebrew denominal verbs and Output-Output correspondence. Phonology 16, 401-42.

Vaux, Bert. 1998. The laryngeal specifications of fricatives. LI 29.3, 497-511.

Viljoen, J. J. 1973. Manual for Ndonga. Part 1. Pretoria: University of South Africa

Walker, Rachel. 1998. Nasalization, Neutral Segments, and Opacity Effects. PhD dissertation, University of California, Santa Cruz. [Published by Garland, New York, 2000].

- 1999. Consonantal correspondence. To appear in Proceedings of the Workshop on the Lexicon in Phonetics \& Phonology, Papers in Experimental and Theoretical Linguistics 6 University of Alberta.

- 2000a. Long-distance consonantal identity effects. WCCFL 19, pp. 532-545. 26.

Walker, Rachel \& Geoffrey K. Pullum. 1999. Possible and impossible segments. $\operatorname{Lg} 75,764-80$.

Walsh-Dickey, Laura. 1997. The Phonology of Liquids. PhD dissertation, University of Massachusetts, Amherst.

Webb, Nancy. 1965. Phonology and noun morphology of the Kindibu dialect of Kikongo. MA thesis, UCLA.

Yip, Moira. 1989. Feature geometry and co-occurrence restrictions. Phonology 6, 349-74.

- 1997. Repetition and its avoidance: The case of Javanese. Proceedings of the 1995

Southwestern Workshop on Optimality Theory (SWOT). ed. by Keiichiro Suzuki \& Dirk Elzinga. Coyote Papers 5, 238-62. University of Arizona.

Zuraw, Kie. 2000. Exceptions and Regularities in Phonology. PhD dissertation, UCLA.

Sharon Rose

University of California, San Diego

Department of Linguistics

9500 Gilman Drive

La Jolla, CA 92093-0108

sxrose@ucsd.edu
Rachel Walker

University of Southern California

Department of Linguistics

Grace Ford Salvatori 301

Los Angeles, CA 90089-1693

rwalker@usc.edu 